\title{
A statistical framework to explore ontogenetic growth variation among individuals and populations: a marine fish example
}

\author{
John R. Morrongiello ${ }^{1}$ and Ronald E. Thresher \\ CSIRO Marine and Atmospheric Research, Wealth from Oceans Flagship, GPO Box 1538, Hobart, Tasmania 7001 Australia
}

\begin{abstract}
Growth is a fundamental biological process, driven by a multitude of intrinsic (within-individual) and extrinsic (environmental) factors, that underpins individual fitness and population demographics. Focusing on the comprehensive information stored in aquatic and terrestrial organism hard parts, we develop a series of increasingly complex hierarchical models to explore spatial and temporal sources of growth variation, ranging in resolution from within individuals to across a species. We apply this modeling framework to an extensive data set of otolith increment measurements from tiger flathead (Platycephalus richardsoni), a demersal commercially exploited fish that inhabits the warming waters of southeast Australia. We recreated growth histories (biochronology) up to four decades in length from seven fishing areas spanning this species' range. The dominant pattern in annual growth was an age-dependent, allometric decline that varied among individuals, sexes, fishing areas, years, and cohorts. We found evidence for among-area differences in growth-rate selectivity, whereby younger fish at capture were generally faster growers. Temporal growth variation was partitioned into two main sources: extrinsic year to year annual fluctuations in environmental conditions and persistent cohortspecific growth differences, reflecting density dependence and/or juvenile experience. Despite low levels of among-individual growth synchrony within areas, we detected a regionally coherent signal of increasing average growth rate through time, a trend related to oceanic warming. At the southerly (poleward) range limit, growth was only weakly related to temperature, but farther north in warmer waters this relationship strengthened until closer to the species' equatorward range limit, growth declined with increasing temperatures. We partitioned these species-wide and area-specific phenotypic responses into within- and among-individual components using a reaction norm approach. Individual tiger flathead likely possess sufficient growth plasticity to successfully adapt to warming waters across much of their range, but increased future warming in the north will continue to depress growth, affecting individual fitness and even population persistence. Our modeling framework is directly applicable to other long-term, individual-based, data sets such as those derived from tree rings, corals, and tag-recapture studies, and provides an unprecedented level of resolution into the drivers of growth variation and the ecological and evolutionary implications of environmental and climatic change.
\end{abstract}

Key words: climate change response functions; dendrochronology; density dependence; fishery-induced evolution; food web; mixed-effect models; multiple drivers; phenotypic plasticity; physiology; reaction norm; tiger flathead; time series analysis.

\section{INTRODUCTION}

Detecting and attributing change in ecology can be difficult due to the multitude of potential natural and anthropogenic driving factors, as well as the underlying complexity of responses at individual, population, species, and assemblage scales (Harley et al. 2006, Parmesan et al. 2011). Insight into ecological change is therefore best achieved by collecting data on a scale commensurate to its likely causes and consequences (Hewitt et al. 2007) or through the development of an understanding of the key physiological mechanisms that underpin observed responses (Portner 2001, Kearney and Porter 2009). Too often, however, inferences have to

Manuscript received 13 February 2014; revised 30 May 2014; accepted 25 June 2014; final version received 31 July 2014. Corresponding Editor: N. T. Hobbs.

${ }^{1}$ E-mail: jrmorrongiello@gmail.com be drawn from short-term and small-scale observational studies and from experiments that are limited in scope relative to the suite of potential interacting processes and drivers. This is particularly true for marine organisms and environments, for which long-term data sets are relatively sparse (Richardson and Poloczanska 2008, Morrongiello et al. 2012) and detailed observational and experimental studies often logistically difficult (e.g., for deep sea habitats and large-bodied fishes).

A complementary approach that can generate long-term data sets against which hypotheses can be framed and tested is the analysis of historical variability in individual growth rates proxied in the hard parts of a diversity of aquatic organisms, e.g., fishes (Thresher et al. 2007); molluscs (Black 2009); corals (De'ath et al. 2009); turtles (Avens et al. 2012); cetaceans (Dellabianca et al. 2012). Analogous to tree-ring-based dendrochronology (Fritts 1976), the widths of periodically deposited increments in 
shells, bones, teeth, scales, and otoliths can provide estimates of daily or annually resolved growth (reviewed by Campana and Thorrold 2001). Large collections of hard parts and associated data sets have been archived for other purposes, e.g., fisheries (Campana and Thorrold 2001) and museums (Pyke and Ehrlich 2010), but their value as archives of long-term ecological biochronologies is generally underappreciated (Morrongiello et al. 2012).

Fish growth has traditionally been analyzed using two techniques that utilize hard-part-derived information. The first approach takes the age and length of multiple individuals at capture and uses equations such as the von Bertalanffy growth function to generate estimates of maximum size $\left(L_{\infty}\right)$ and the rate at which this is reached $(K)$. While this approach generally has a populationaverage and time-invariant focus, it can readily be expanded to include individual-level effects (e.g., Sainsbury 1980, Pilling et al. 2002, Eveson et al. 2007) and used to explore environmental and temporal trends if timeseries data are available (e.g., Rowling and Reid 1992, Shelton et al. 2013, Baudron et al. 2014). The second approach, termed back-calculation, uses hard-part increment measurements in conjunction with the length at capture to estimate an individual's length at the time of increment formation (Francis 1990). Back-calculation has been successfully used in ecological contexts (e.g., Sinclair et al. 2002a, b), although individual-specific variation is generally ignored (but see Tonkin et al. 2011) and the approach can result in significantly biased inference if not correctly applied (Campana 1990). Accessing and appropriately analyzing these long-term, individual-based data sets stored in archived hard parts could make possible detailed analysis and attribution of spatial, temporal, and individual sources of growth variability in aquatic environments on unprecedented scale and coverage (for terrestrial examples, see Clutton-Brock and Sheldon 2010). In particular, allowing for among-individual growth variation and investigating phenotypic plasticity through individual reaction norms can provide a means of decomposing population level variation into its within- and among-individual components. This in turn aids ecological and evolutionary interpretation of historical growth patterns and facilitates more accurate prediction of biological responses to future environmental change (Miner et al. 2005, Nussey et al. 2007).

Growth is a biological response that inherently integrates the effects of many interacting intrinsic (e.g., ontogenetic or individual-specific differences) and extrinsic (environmental or intra- and interspecific interactions) components. Using proxied biochronological growth data to address ecological and behavioral hypotheses therefore requires an ability to attribute variance appropriately. Our paper explores options for doing so, with the objective of generating a more complete picture and understanding of an organism's response to environmental change, ranging from within the individual to across the species. The increment data in aquatic hard parts is inherently hierarchical: repeated (daily, annual) measurements are taken from each of many individuals that in turn span overlapping years, cohorts, and populations. Our approach to analyzing this hierarchical time-series data follows Weisberg (1993), then Weisberg et al. (2010), who proposed the use of, first, fixed-effect and subsequently, mixed-effects models to analyze increment data as a means of capturing both intrinsic and extrinsic sources of growth variation. Mixed-effect models are particularly useful as random effect structures can more accurately represent the data's hierarchy (Morrongiello et al. 2014) and are sufficiently flexible as to allow testing of within vs. among individual (Dingemanse and Dochtermann 2013) and population-level (Leites et al. 2012) differences in phenotypic expression along environmental gradients. While somewhat complex, such models potentially utilize all available biological information encoded in the historical proxy and allow for the concurrent exploration of ecological, physiological, and evolutionary responses to changing environmental conditions through time and across a species' range. Indeed, these are important points of difference from the more traditional hard-part analysis approaches (e.g., dendrochronology) that have focused on maximizing the detection of environmental signals through the minimization of ecological, physiological, and genetic sources of noise using various detrending and prewhitening techniques prior to data analysis (Cook and Kairiukstis 1990).

We develop and apply to a test species a series of increasingly complex mixed-effect models and assess at each stage the extent to which the model adequately partitions growth variability among a series of intrinsic (individual, age, sex, cohort) and extrinsic (time, temperature, fishery activity, spatial structure) components. From this analysis, we develop model structures that facilitate interpretation of biochronological information in an ecological context (sensu Morrongiello et al. 2012). We then expand these ecological models to investigate evolutionary sources of variability that would not have been evident in simpler approaches.

Our test species is a commercially exploited fish, tiger flathead (Platycephalus richardsoni), for which we developed a database of otolith increment measurements from across its range in southeast Australia. Otoliths are biogenic carbonate structures in the inner ear equivalents of fishes that serve in the detection of movement and orientation. Otoliths are well validated across diverse fish species to form annual growth increments and are widely used by fisheries scientists and fish ecologists for purposes of studying age and growth in fishes (Campana 2001). As tiger flathead is a commercially exploited species, we were able to access a very large data set of high-quality otolith increment measurements taken as an integral part of a fisheries management program, which we supplemented to fill in data gaps for specific regions and times. We also chose this species for analysis on the basis that southeast Australia has been identified as a climate change hotspot, having experienced rapid recent warming above 

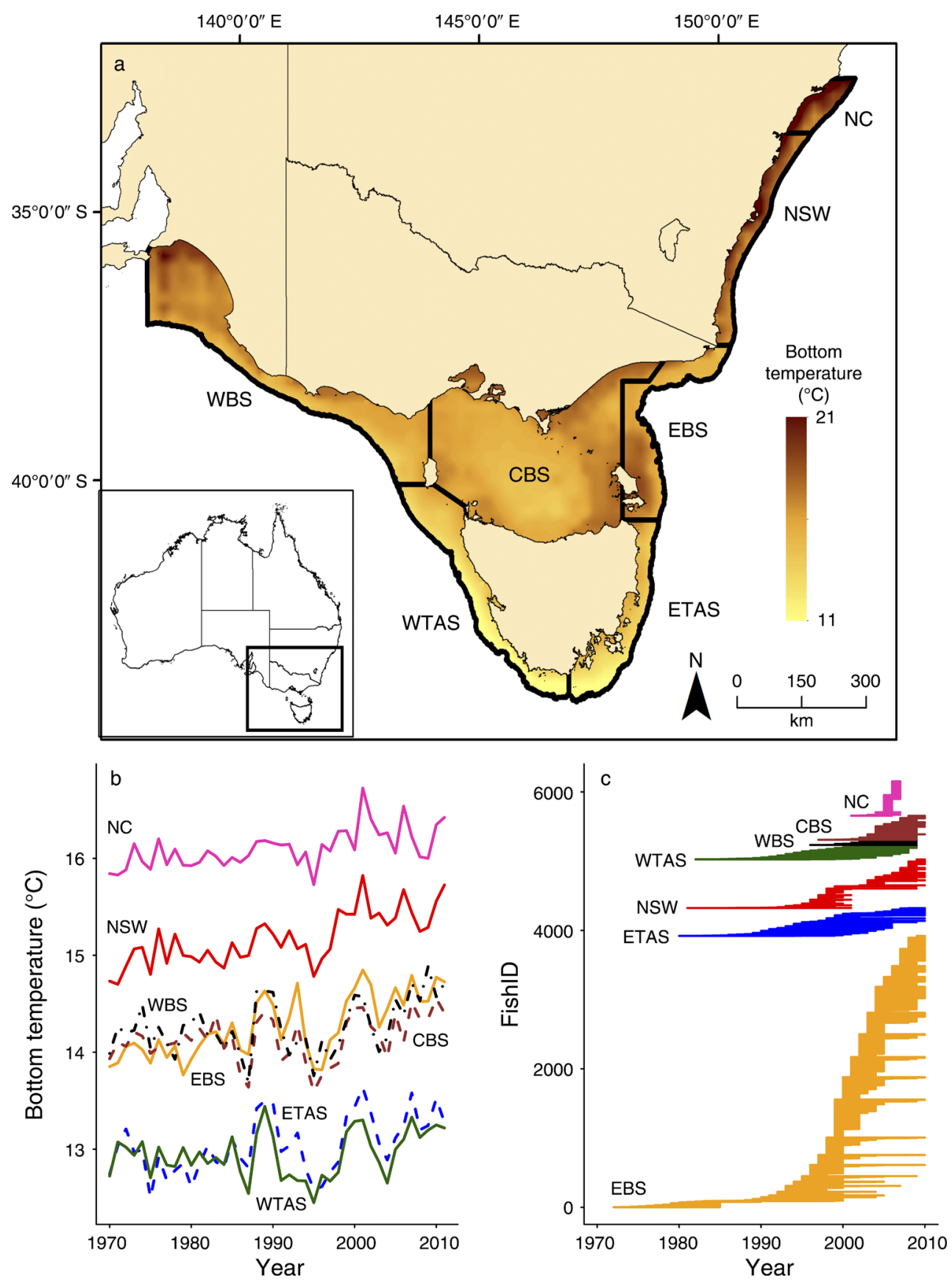

FIG. 1. (a) Map of southeast Australia showing locations of the seven fishing areas used in this study and spatial patterns in mean bottom temperature (30-250 $\mathrm{m}$ depth) over the period 1970-2011. (b) Temporal trends in mean bottom temperature for the seven fishing areas. (c) Spatial and temporal range of fish samples used in analyses. Each line represents an individual tiger flathead Platycephalus richardsoni (uniquely identified by a number, the FishID variable, $F$ ); the left end starts when they were spawned (i.e., year class) and the right when they were sampled. Line length therefore represents the temporal extent of data. NC, Newcastle region; NSW, New South Wales; EBS, eastern Bass Strait; ETAS, eastern Tasmania; WTAS, western Tasmania; WBS, western Bass Strait; and CBS, central Bass Strait.

the global average (Ridgway 2007, Hobday and Lough 2011) and concordant ecological change (Johnson et al. 2011). This locally strong environmental signal could be useful in disentangling the relative impacts of extrinsic and intrinsic components of growth as recorded in the otolith biochronologies.

\section{Methods}

Study species

Tiger flathead are a common, carnivorous, dermersal species inhabiting the continental shelf (range 30-350 m, most common $<200 \mathrm{~m}$ ) of southeast Australia (Fig. 1; 
TABLE 1. Summary of tiger flathead samples used in this study.

\begin{tabular}{lcccrcrrrr}
\hline \hline Area & $\begin{array}{c}\text { Central } \\
\text { latitude }\left({ }^{\circ} \text { S) }\right.\end{array}$ & $\begin{array}{c}\text { Central } \\
\text { longitude }\left({ }^{\circ} \mathrm{E}\right)\end{array}$ & $\begin{array}{c}\text { No. sample } \\
\text { years }\end{array}$ & $\begin{array}{c}\text { No. } \\
\text { fish }\end{array}$ & $\begin{array}{c}\text { No. increment } \\
\text { measurements }\end{array}$ & $\begin{array}{c}\text { Age } \\
\text { range }(\mathrm{yr})\end{array}$ & $\begin{array}{c}\text { No. year } \\
\text { classes }\end{array}$ & $\begin{array}{c}\text { Biochronology } \\
\text { length }(\mathrm{yr})\end{array}$ & $\begin{array}{c}\text { Range } \\
\text { of years }\end{array}$ \\
\hline NC & 33 & 152.2 & 2 & 498 & 640 & $2-6$ & 6 & 6 & $2001-2006$ \\
NSW & 35.4 & 150.9 & 7 & 700 & 1899 & $2-18$ & 21 & 29 & $1981-2009$ \\
WBS & 37.9 & 141.3 & 2 & 75 & 310 & $2-14$ & 12 & 13 & $1996-2008$ \\
EBS & 39.2 & 149.0 & 14 & 3915 & 15786 & $2-25$ & 38 & 38 & $1972-2009$ \\
CBS & 39.6 & 145.8 & 2 & 344 & 1454 & $2-13$ & 11 & 13 & $1997-2009$ \\
ETAS & 42.3 & 147.4 & 6 & 402 & 2822 & $2-21$ & 28 & 30 & $1980-2009$ \\
WTAS & 42 & 145.1 & 2 & 208 & 1735 & $3-28$ & 22 & 27 & $1982-2008$ \\
\hline
\end{tabular}

Note: NC stands for Newcastle region, NSW stands for New South Wales, EBS stands for eastern Bass Strait, ETAS stands for eastern Tasmania, WTAS stands for western Tasmania, WBS stands for western Bass Strait, and CBS stands for central Bass Strait.

Gomon et al. 2008, Woodhams et al. 2011). Individuals grow $\sim 65 \mathrm{~cm}$ in length, weigh up to $2.5 \mathrm{~kg}$, and live to 28 years (Table 1; see Gomon et al. 2008). Sexual maturity is reached after 4-5 years, and spawning occurs during the austral spring to summer months (September-February; Woodhams et al. 2011), with a birth date of 1 January assigned for aging purposes. Tiger flathead have been targeted by commercial fishers since 1915, with the fishery developing first in the waters off New South Wales then spreading farther south (Tilzey and Rowling 2001). The stock structure for tiger flathead remains poorly understood: there is some evidence for regional differences in morphology, age, growth, and timing of reproduction (Sahqvist et al. 2012), and tagging studies and trawl catches suggest minimal along-shelf movement ( $<50$ nautical miles [92.6 km] or $\sim 1^{\circ}$ latitude; reviewed in Rowling 1994). No formal stock identification studies have been carried out, and thus a single continuous stock is assumed for management purposes (Sahqvist et al. 2012).

\section{Biochronology development and analysis}

Study area and sample collection.-The continental shelf waters inhabited by tiger flathead are divided, for the purpose of fishery stock assessments, into six Commonwealth fishing areas (Fig. 1a): New South Wales (NSW, zone 10), eastern Bass Strait (EBS, zone 20), eastern Tasmania (ETAS, zone 30), western Tasmania (WTAS, zone 40), western Bass Strait (WBS, zone 50), and central Bass Strait (CBS, zone $60)$. Fisheries observers routinely collect tiger flathead otoliths from commercial operations in each of these areas to provide age estimates of the commercial catch for stock assessment modeling (Knuckey et al. 1999). Port of landing information is only available for some samples, and thus we assign a fish's geographic origins only to a fishing area. While this results in geographically conservative estimates of where fish resided, it better reflects underlying uncertainty of where fish have been throughout their lives due to any seasonal, ontogenetic, or permanent movement. The northern extent of tiger flathead's range is managed by NSW State fisheries and otoliths are opportunistically collected from these fish, with adequate samples only available from fish collected in the Newcastle region (NC; Fig. 1a). Overall, we accessed archived increment measurements from 5781 fish and supplemented these with measurements from an additional 362 fish. In total, 24661 increments from 6143 tiger flathead collected across the seven fishing areas, representing the majority of this species' range, were analyzed (Fig. 1a, c, Table 1). For the reasons noted above, the $\mathrm{NC}$ data set was restricted in temporal scope and age range compared to other areas.

Increment width measurements. - The flathead otoliths were prepared and aged by experienced staff for the Commonwealth fishery by the Central Ageing Facility (CAF; Morison et al. 1998) and Fish Ageing Services (FAS) and for the NSW state fishery by the Cronulla Fisheries Research Centre (Barnes et al. 2011). All otoliths were embedded in resin and sectioned transversely at a width of between 300 and $500 \mu \mathrm{m}$ through the primodium. Sections were then mounted on a glass microscope slide, viewed under transmitted light, and aged along a consistent axis on the ventral lobe of the otolith (Fig. 2a). Aging precision (reproducibility of repeated measurements), measured by the coefficient of variation, averaged $2.9 \%$ for CAF and FAS, and $7 \%$ for Barnes et al. (2011) samples; $~ 90 \%$ of aging discrepancies between repeated readings were within one year (unbiased to either younger or older ages). Increment widths are routinely recorded during this aging process using image analysis software and archived along with sample information. The use of otolith increment data to reconstruct growth histories assumes otolith growth is proportional to somatic growth (Campana 1990, Francis 1990). We tested and satisfied this assumption by correlating otolith size to fish size (Appendix A).

Average annual bottom temperature.-We estimated average annual temperature (Temperature) at the seafloor (depth 30-250 m) for each area (Fig. 1a, b) over the period 1970-2011 using a combination of SynTS (synthetic temperature and salinity; Ridgway et al. 2006) and HadISST1 (Rayner et al. 2003) modeled products (Appendix B). Bottom Temperature for the period 1970-2011 displayed coherent interannual variability within an area and latitudinal variability among areas (Fig. 1a,b). Bottom temperatures significantly 
increased through time across most fishing areas at a rate of between $0.005^{\circ} \mathrm{C}$ per year and $0.019^{\circ} \mathrm{C}$ per year (Appendix B).

Catch data.-Commercial trawl fishery catch and effort data were used to calculate an index of relative abundance (based on catch per unit effort [CPUE] kg/h) for the six Commonwealth fishing areas following the methods of Haddon (2011; Appendix C) and published mean CPUE estimates for the whole state of NSW for NC (state-managed fishery; Rowling et al. 2010). Abundance estimates for areas NSW, EBS, CBS, WBS, and ETAS were available from 1986 onward. Tiger flathead are never caught in large numbers in WTAS, so abundance estimates for this area were only available from 2000 onward. Temporal trends in abundance estimates varied considerably among fishing areas (Appendix C).

Growth statistical analyses.-We developed a series of mixed-effects models to investigate intrinsic and extrinsic sources of tiger flathead annual growth (increment width in $\mathrm{mm}$ ) variation within and among fishing areas. We provide an overview of model parameters and general model structure. Specific hypotheses and model formulations are described and examined in more detail in Results and Discussion. Fixed intrinsic predictors of annual growth were fish Age, Sex, and Age at capture (Table 2). The latter term tests for bias and differential selectivity in the data (Ricker 1969, Morrongiello et al. 2012; see Nehrbass-Ahles et al. [2014] for discussion of potential biases in dendrochronology studies) and is similar in purpose to the length term in Hagen and Quinn's otolith-based growth model (1991). Although we only fit a linear Age-at-capture term and explore potential directional (positive and negative) selection; quadratic or nonlinear terms could potentially also be fitted to explore other types of selection, such as stabilizing or disruptive or a combination of these (e.g., Sinclair et al. 2002a). Fixed extrinsic predictors included temporal growth trends (Year), water temperature at the seafloor (Temperature) fitted as linear and quadratic terms to investigate any curvilinear growth responses, and potential density-dependent effects on growth (relative Abundance; Table 2)

A likely inherent property of the data is that repeated increment measurements within a fish will be more similar to each other than to those of other fish because of individual-specific differences in growth rates. It is also possible that there is some form of temporal correlation among individual measurements within a fish due to measurement error (an overestimate of increment width in year one will necessarily mean the measurement of year two is lower and vice versa). The fish sampled are also seen as a random draw of all possible fish in a population. To accommodate these in the model, we include a random intercept for FishID $\left(\alpha_{i}^{F}, i=1, \ldots, I\right)$, where $F$ is FishID and $i$ is fish, which induces a correlation among increment measurements within a fish and allows each individual to have higher
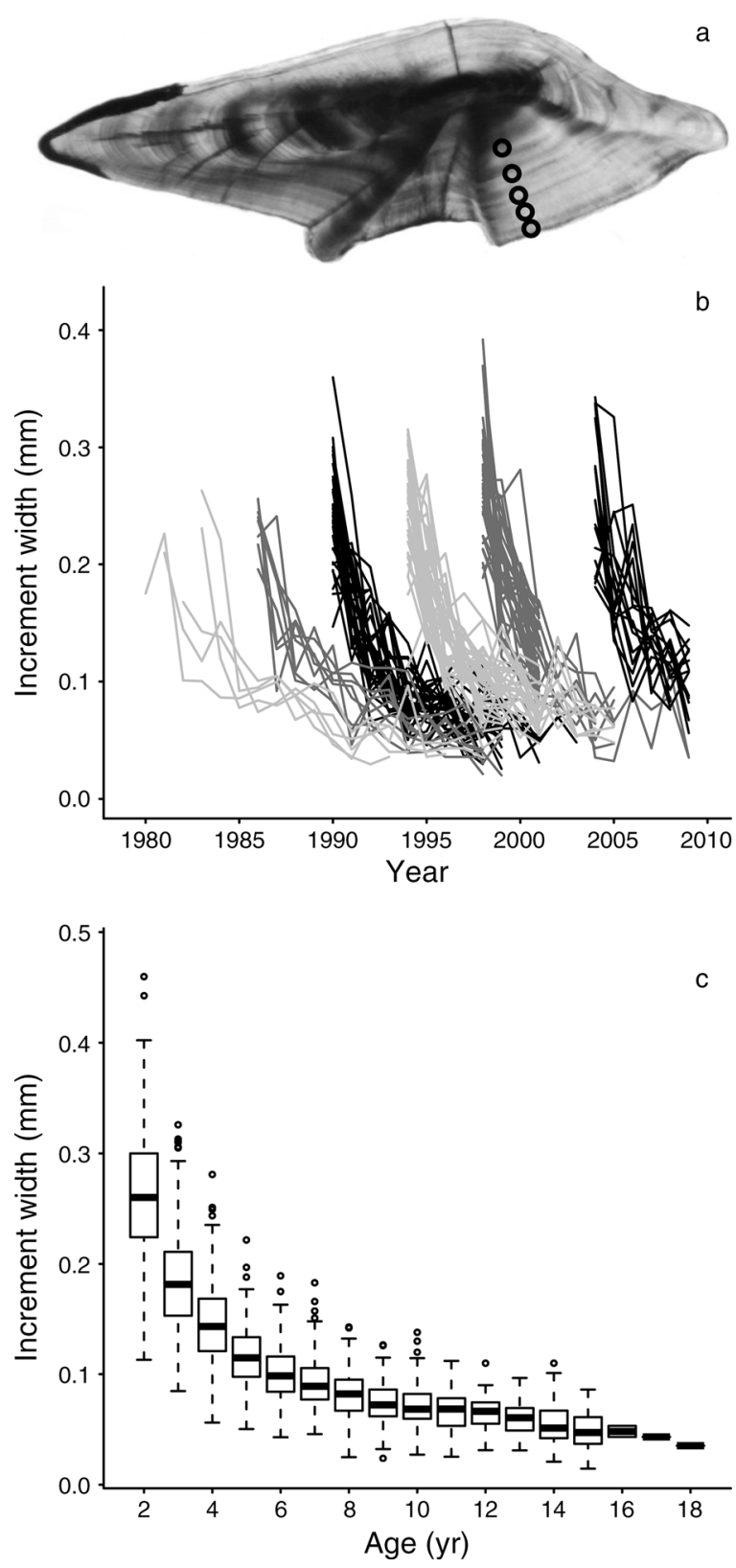

FIG. 2. An example from ETAS of the data analyzed in this study. (a) Transverse section of a sagittal otolith from a five-year-old ETAS tiger flathead from the 2004 cohort, caught in 2010. Fish are aged and their increments (annuli) measured along an axis ventral to the sulcus (open circles). (b) Increment measurements for selected cohorts of ETAS fish (different line shades; 1979-1982, 1985, 1989, 1993, 1997, 2003) plotted by year of formation (birth year plus age). (c) Box and whisker plots of increment measurements by age of formation for all ETAS fish. The bar represents the median; box height is the interquartile range (IQR; 25th to 75th percentile); whiskers are the highest and lowest measurements within $1.5 \times$ IQR of the 75 th and the 25 th percentiles, respectively; circles are outliers. 
TABLE 2. Description of parameters used in the analysis of tiger flathead annual growth.

\begin{tabular}{ll}
\hline \hline Parameter & \\
\hline Fixed effects & Description \\
Age & Age (yr) when otolith increment was formed. \\
Sex & Male or female. \\
Age at capture & Final age $(\mathrm{yr})$ at time of capture. Measure of potential selectivity on growth. \\
Year & Year $(1$ Jan-31 Dec) in which increment was formed. Used to quantify temporal trends in growth. \\
Temperature & Annual average temperature $\left({ }^{\circ} \mathrm{C}\right)$ at seafloor. \\
Abundance & Annual catch per unit effort $(\mathrm{CPUE})$. \\
AvTemp & Area-specific temperature normal $($ long-term average). Quantifies spatial differences in Temperature. \\
TempAnom & Area-specific annual departures from AvTemp. Quantifies a region's temporal Temperature stochasticity. \\
$\beta_{\mathrm{A}}$ & Coefficient for an individual's average lifetime Temperature experienced. Quantifies systematic among- \\
$\beta_{\mathrm{W}}$ & individual (subscript A) differences in temperature response. \\
& Coefficient for individual-specific annual departures from $\beta_{\mathrm{A}}$. Quantifies the average within-individual \\
Random effects & (subscript W) phenotypic plasticity in thermal reaction norms. \\
FishID $(F)$ & Unique identifier number for each fish $(i=1, \ldots, I)$. \\
Year $(Y)$ & Year $(1$ Jan-31 Dec; $k=1, \ldots, K)$ in which increment was formed. Quantifies inter-annual growth \\
& variability. \\
Cohort $(C)$ & Group of individuals spawned in the same year $(l=1, \ldots, L)$. \\
Area $(A)$ & Fishing area $(m=1, \ldots, 7)$. \\
Age & Random Age slope on each of FishID, Year, Cohort, and Area random intercepts. \\
$\beta_{\mathrm{W}}$ & Random within-individual reaction norm slope on FishID. Facilitates exploration of among-individual \\
& variation in individual reaction norms. \\
\hline
\end{tabular}

or lower growth than average (i.e., model's overall intercept). These individual-specific deviations can be due biological and/or measurement error processes. Unless otherwise noted, all models include the FishID random intercept and an Age fixed effect. Likewise, extrinsic factors are expected to exert similar effects on all individuals experiencing a common set of environmental conditions. Including a random intercept for Year (seen as random draw of all possible years; crossed with FishID) induces a correlation among increments from different fish deposited in the same year. The Year ( $Y$ ) random intercepts $\left(\alpha_{k}^{Y}, k=1, \ldots, K\right)$, where $k$ is year, are the simplest population biochronology, analogous to outputs from classical dendrochronology, as they pool the effects of different extrinsic sources of growth variation after effects of intrinsic factors (Age, Sex, Age at capture) are explicitly accounted for. These coefficients provide temporally resolved estimates of whether conditions were good or poor for growth in a given year as compared to the long-term average (i.e., model's overall intercept). We do not assume any temporal directionality in these year to year growth deviations but do assume they are random draws from a normal distribution. A random intercept for Cohort $\left(\alpha_{l}^{c}\right.$, $l=1, \ldots, L$; FishID nested within Cohort), where $C$ is cohort, induces a correlation among the growth of individuals spawned in the same year, $l$. Cohort also provides a temporally resolved estimate of combined intrinsic and extrinsic growth variation (again, no directionality assumed), but rather than being annual, it captures systematic deviations in growth for groups of fish across their lifetime. We also explored whether the addition of random Age slopes $(b)$ for FishID $\left(b_{1 i}^{F}\right)$, Year $\left(b_{1 k}^{Y}\right)$, and Cohort $\left(b_{1 l}^{C}\right)$ improve model performance. Among-area models additionally include a random intercept for Area $\left(\alpha_{m}^{A}, m=1, \ldots, 7\right)$, where $m$ is site and $A$ is area, within which FishID, Year, and Cohort can be nested, as well as random slopes for Age and Age at capture by Area ( $b_{1 m}^{A}$ and $b_{2 m}^{A}$, respectively). A descriptive summary of random effects is presented in Table 2, and a presentation of models fitted in Table 3.

All analyses were performed using the lme4, AICcmodavg, and effects packages in the statistical program R 3.0.2 (R Development Core Team 2013). Annual growth, Age, and Age at capture were natural log-transformed to satisfy model assumptions, and all predictor variables were mean-centered to facilitate model convergence and interpretation of interaction and polynomial terms. The lme4 package only allows for a compound symmetric correlation structure. This assumes that the residual correlation between any two observations within a group (e.g., FishID) is the same regardless of the time difference. Compound symmetry does have applicability in models with short time series per group (as is generally the case here for each fish; Pinheiro and Bates 2000:228), although perhaps a more appropriate method (not available in lme4) would be an autoregressive process (e.g., AR-1). The addition of a crossed Year random intercept can account for some autocorrelation in the data (e.g., Morrongiello et al. 2011), and model estimates are generally robust to the choice of covariance structure (Zeger and Liang 1986, Weisberg et al. 2010). Another potential issue with likelihood-based models such as those presented here is that they do not allow for measurement error in the predictor variable (e.g., aging error). In this instance, aging precision was high, and there was no directional bias so errors will likely just add noise to any existing biological patterns. Other time-series-based approaches such as Bayesian state-space modeling offer an attractive 
and more flexible alternative for this kind of hierarchical analysis, as they allow for the joint estimation of both process stochasticity and measurement error in both the predictor and response variable and the incorporation of prior knowledge (for tree and fish growth examples, see Clark et al. 2007 and Shelton et al. 2013).

Analyses of random effects were performed by fitting the desired model structure using restricted maximum likelihood estimates of error (REML). Models with increasing fixed-effect complexity were fitted using maximum likelihood estimates of error. Methods to select among competing hierarchical models (in both likelihood and Bayesian paradigms) is an area of active research, with no general consensus among statisticians as to what approach is best to adopt (Bolker et al. 2009, Wang and Gelman 2014, Hooten and Hobbs 2015). Nonetheless, the ultimate aim of virtually all model selection methods is to choose the model that would have the best ability to predict out of sample data. We assessed the relative support for each candidate set of the models using Akaike's information criterion corrected for small sample size $\left(\mathrm{AIC}_{\mathrm{c}}\right.$; Burnham and Anderson 2002). $\mathrm{AIC}_{\mathrm{c}}$ values were rescaled as the difference between each model and the model with the lowest $\mathrm{AIC}_{\mathrm{c}}(\Delta \mathrm{AIC})$. Best models were then reanalyzed using REML to produce unbiased parameter estimates (Zuur et al. 2009).

An issue with applying our approach to mixed-effect model selection is that AIC requires a count of model degrees of freedom (df) to apply a penalty for model complexity; how random effects are treated depends on the level of inference being made. If model selection is occurring on fixed effects (with a constant randomeffects structure across models), then inference is being made at population or marginal level and each random effect can be assigned one df. Traditional, or marginal AIC, as applied here is appropriate (Vaida and Blanchard 2005), and random effects can be seen as just modeling underlying correlation structures (Claeskens and Hjort 2008:270). If, however, one wants to select and interpret random effects themselves, then conditional inference is being made (Vaida and Blanchard 2005), and the number of $\mathrm{df}$ for a random effect is somewhere between 1 and $N-1$, where $N$ is the number of clusters within a random effect. It has been proposed that the conditional AIC be used to select among different random effect structures (Vaida and Blanchard 2005), although its calculation is nontrivial (Greven and Kneib 2010) and not currently implemented in the lme4 package. Other random-effect model selection options include standard likelihood-based hypothesis tests (conservative; Bolker et al. 2009) and out of sample or crossvalidation techniques (Hooten and Hobbs 2015). The latter two options are appealing, as they provide an assessment of a model's predictive ability, but extracting predicted values from models with complex randomeffects structures is not currently possible with lme4, and there is some conjecture over how holdout data is selected (Wang and Gelman 2014). We therefore acknowledge that our application of the marginal AIC to select among random-effects structures will lead to a bias toward smaller models without random effects (Greven and Kneib 2010) and that other options may result in better multimodel inference, such as prediction. Here, the importance of each random effect is likely to be underestimated, and we therefore consider our results conservative.

We estimated the degree of correlation among growth increments from individuals (temporal growth synchrony) for Year and Cohort by calculating the intraclass correlation coefficient (ICC) for random intercept-only models (Appendix D: Eq. D.1). The amount of variance explained by models was assessed using two $R^{2}$ metrics (calculated on models fit with REML) defined for mixed-effects models by Nakagawa and Schielzeth (2013). The first, called the marginal $R^{2}\left(R_{\mathrm{LMM}(\mathrm{m})}^{2}\right)$, where LMM is linear mixed-effects model, describes the proportion of variance explained by fixed effects alone. The second, called the conditional $R^{2}\left(R_{\mathrm{LMM}(\mathrm{c})}^{2}\right)$, describes the proportion of variance explained by fixed and random effects combined (see Appendix D: Eqs. D. 2 and D. 3 for definitions).

Each area's data set was broken into two time periods for analysis based on the temporal extent of predictor variables. The first data set, encompassing the full growth record (Table 1), was used to partition growth variation among intrinsic and extrinsic components and to investigate temporal trends and temperature effects within and across areas. The second data set spanned a shorter period, corresponding to the availability of Abundance estimates (Methods: Biochronology development and analyses: Catch data), and was used to investigate the relative importance of Abundance and Temperature on annual growth within regions. We provide R code and example data sets in the Supplement.

\section{Results And Discussion}

\section{Intrinsic sources of growth variation}

Across all specimens and increments, the most important factor determining growth rate variation in tiger flathead, as in almost all fish species, was Age (i.e., growth rates decline with increasing Age; Fig. 2). All other ecological and physiological implications derived from a growth rate proxy are based on interrogating the remaining variance.

As a first step to represent the data's underlying hierarchical structure and accurately partition growth variance among its intrinsic and extrinsic sources, we adopted a mixed-modeling framework and included a random intercept (FishID) for each fish (Table 3; model 1a). This model allows for and quantifies the magnitude of individual-specific deviations from average growth, but still assumes that age-dependent growth declines in the same manner across individuals. Hence, model 1b (Table 3) allows for individual- 
TABLE 3. Description of hierarchical models used to partition growth variation into its intrinsic and extrinsic components.

\begin{tabular}{ccc}
\hline \hline Model no. & Formulation & Parameter descriptions \\
\hline
\end{tabular}

a) Within-area

1a: random FishID intercept

1b: random Age slope and intercept for each FishID

2a: random Age slope and intercept for each FishID and random Year intercept

2b: random Age slope and intercept for each FishID and random Cohort intercept

3a: random Age slopes and intercepts for each FishID and Year

3b: random Age slopes and intercepts for each FishID and Cohort

4a: random Age slopes and intercept for each FishID, and random Year and Cohort intercepts

4b-4d: random Age slopes and intercept for each FishID, with combinations of random Age slopes for Year and Cohort intercepts. Shown is 4d (most complex)

b) Across area

5: random Age slopes for each FishID; FishID, Year and Cohort nested within random intercept for Area

6: random Age slopes for each FishID, Year, and Cohort nested within Area; random Age and Age at capture slopes for each Area

$$
\begin{aligned}
& y_{i j}=\alpha_{0}+\alpha_{i}^{F}+\beta_{1} x_{i j}+f(\cdot)+\varepsilon_{i j} \\
& \alpha_{i}^{F} \sim N\left(0, \sigma_{F}^{2}\right), \varepsilon_{i j} \sim N\left(0, \sigma^{2}\right)
\end{aligned}
$$$$
\begin{aligned}
& y_{i j}=\alpha_{0}+\alpha_{i}^{F}+\beta_{1} x_{i j}+b_{1 i}^{F} x_{i j}+f(\cdot)+\varepsilon_{i j} \\
& {\left[\begin{array}{c}
\alpha_{i}^{F} \\
b_{1 i}^{F}
\end{array}\right] \sim N\left(0, \Sigma_{i}\right), \varepsilon_{i j} \sim N\left(0, \sigma^{2}\right)}
\end{aligned}
$$$$
y_{i j k}=\alpha_{0}+\alpha_{i}^{m F}+\alpha_{k}^{Y}+\beta_{1} x_{i j}+b_{1 i}^{F} x_{i j}+f(\cdot)+\varepsilon_{i j k}
$$$$
\left[\begin{array}{c}
\alpha_{i}^{F} \\
b_{1 i}^{F}
\end{array}\right] \sim N\left(0, \Sigma_{i}\right), \alpha_{k}^{Y} \sim N\left(0, \sigma_{Y}^{2}\right), \varepsilon_{i j k} \sim N\left(0, \sigma^{2}\right)
$$$$
y_{i j l}=\alpha_{0}+\alpha_{i}^{F}+\alpha_{l}^{C}+\beta_{1} x_{i j}+b_{1 i}^{F} x_{i j}+f(\cdot)+\varepsilon_{i j l}
$$$$
\left[\begin{array}{c}
\alpha_{i}^{F} \\
b_{1 i}^{F}
\end{array}\right] \sim N\left(0, \Sigma_{i}\right), \alpha_{l}^{C} \sim N\left(0, \sigma_{C}^{2}\right), \varepsilon_{i j l} \sim N\left(0, \sigma^{2}\right)
$$$$
y_{i j k}=\alpha_{0}+\alpha_{i}^{F}+\alpha_{k}^{Y}+\beta_{1} x_{i j}+b_{1 i}^{F} x_{i j}+b_{1 k}^{Y} x_{j k}+f(\cdot)+\varepsilon_{i j k}
$$$$
\left[\begin{array}{c}
\alpha_{i}^{F} \\
b_{1 i}^{F}
\end{array}\right] \sim N\left(0, \Sigma_{i}\right),\left[\begin{array}{c}
\alpha_{k}^{Y} \\
b_{1 k}^{Y}
\end{array}\right] \sim N\left(0, \Sigma_{k}\right), \varepsilon_{i j k} \sim N\left(0, \sigma^{2}\right)
$$$$
y_{i j l}=\alpha_{0}+\alpha_{i}^{F}+\alpha_{l}^{C}+\beta_{1} x_{i j}+b_{1 i}^{F} x_{i j}+b_{1 l}^{C} x_{j l}+f(\cdot)+\varepsilon_{i j l}
$$$$
\left[\begin{array}{c}
\alpha_{i}^{F} \\
b_{1 i}^{F}
\end{array}\right] \sim N\left(0, \Sigma_{i}\right),\left[\begin{array}{c}
\alpha_{l}^{C} \\
b_{1 l}^{C}
\end{array}\right] \sim N\left(0, \Sigma_{l}\right), \varepsilon_{i j l} \sim N\left(0, \sigma^{2}\right)
$$$$
y_{i j k l}=\alpha_{0}+\alpha_{i}^{F}+\alpha_{k}^{Y}+\alpha_{l}^{C}+\beta_{1} x_{i j}+b_{1 i}^{F} x_{i j}+f(\cdot)+\varepsilon_{i j k l}
$$$$
\left[\begin{array}{c}
\alpha_{i}^{F} \\
b_{1 i}^{F}
\end{array}\right] \sim N\left(0, \Sigma_{i}\right), \alpha_{k}^{Y} \sim N\left(0, \sigma_{Y}^{2}\right), \alpha_{l}^{C} \sim N\left(0, \sigma_{C}^{2}\right), \varepsilon_{i j k l} \sim N\left(0, \sigma^{2}\right)
$$$$
y_{i j k l}=\alpha_{0}+\alpha_{i}^{F}+\alpha_{k}^{Y}+\alpha_{l}^{C}+\beta_{1} x_{i j}+b_{1 i}^{F} x_{i j}+b_{1 k}^{Y} x_{j k}+b_{1 l}^{C} x_{j l}
$$$$
+f(\cdot)+\varepsilon_{i j k l}
$$$$
\left[\begin{array}{c}
\alpha_{i}^{F} \\
b_{1 i}^{F}
\end{array}\right] \sim N\left(0, \Sigma_{i}\right),\left[\begin{array}{c}
\alpha_{k}^{Y} \\
b_{1 k}^{Y}
\end{array}\right] \sim N\left(0, \Sigma_{k}\right),\left[\begin{array}{c}
\alpha_{l}^{C} \\
b_{1 l}^{C}
\end{array}\right] \sim N\left(0, \Sigma_{l}\right),
$$$$
\varepsilon_{i j k l} \sim N\left(0, \sigma^{2}\right)
$$

$$
\begin{aligned}
y_{i j k l m}= & \alpha_{0}+\alpha_{i}^{F}+\alpha_{m}^{A}+\alpha_{k m}^{Y}+\alpha_{l m}^{C}+\beta_{1} x_{i j}+b_{1 i}^{F} x_{i j}+f(\cdot) \\
& +\varepsilon_{i j k l m} \\
{\left[\begin{array}{c}
\alpha_{i}^{F} \\
b_{1 i}^{F}
\end{array}\right] \sim } & N\left(0, \Sigma_{i}\right), \alpha_{m}^{A} \sim N\left(0, \sigma_{A}^{2}\right), \alpha_{k m}^{Y} \sim N\left(0, \sigma_{Y}^{2}\right), \\
& \alpha_{l m}^{C} \sim N\left(0, \sigma_{C}^{2}\right), \varepsilon_{i j k l m} \sim N\left(0, \sigma^{2}\right) \\
y_{i j k l m q}= & \alpha_{0}+\alpha_{i}^{F}+\alpha_{m}^{A}+\alpha_{k m}^{Y}+\alpha_{l m}^{C}+\beta_{1} x_{i j}+b_{1 i}^{F} x_{i j}+b_{1 m}^{A} x_{j m} \\
& +b_{1 k m}^{Y} x_{j k m}+b_{1 l m}^{C} x_{j l m}+\beta_{2} x_{m q}+b_{2 m}^{A} x_{m q}+f(\cdot)+\varepsilon_{i j k l m} \\
{\left[\begin{array}{c}
\alpha_{i}^{F} \\
b_{1 i}^{F}
\end{array}\right] \sim } & N\left(0, \Sigma_{i}\right),\left[\begin{array}{c}
\alpha_{m}^{A} \\
b_{1 m}^{A} \\
b_{2 m}^{A}
\end{array}\right] \sim N\left(0, \Sigma_{m}\right),\left[\begin{array}{c}
\alpha_{k m}^{Y} \\
b_{1 k m}^{Y}
\end{array}\right] \sim N\left(0, \Sigma_{k m}\right), \\
& {\left[\begin{array}{c}
\alpha_{l m}^{C} \\
b_{1 l m}^{C}
\end{array}\right] \sim N\left(0, \Sigma_{l m}\right), \varepsilon_{i j k l m} \sim N\left(0, \sigma^{2}\right) }
\end{aligned}
$$

$y_{i j}$, annual growth $y$ for fish $i$ at age $j ; \alpha_{0}$, overall mean annual growth intercept; $\alpha_{i}^{F}$,random intrinsic effect for fish $i ; \beta_{1}$, fixed-effect

Age coefficient; $f(\cdot)$, additional fixed effects (e.g., Sex or Age at capture); $N$, normally distributed; $\varepsilon$, error

$b_{1 i}^{F}$, random Age slope for fish $i$, correlated with $\alpha_{i}^{F} ; \Sigma$, covariance matrix between random intercept and random slope

$y_{i j k}$, annual growth $y$ for fish $i$ at age $j$ from year $k ; \alpha_{k}^{Y}$, random extrinsic environmental effect for year $k$

$y_{i j l}$, annual growth $y$ for fish $i$ at age $j$ from cohort $l ; \alpha_{l}^{C}$, random intercept for cohort $l$

$b_{1 k}^{Y}$, random Age slope for year $k$, correlated with $\alpha_{k}^{Y}$

$b_{1 l}^{C}$, random Age slope for cohort $l$, correlated with $\alpha_{l}^{C}$

$y_{i j k l}$, annual growth $y$ for fish $i$ at age $j$ from year $k$ and cohort $l$

$y_{i j k l m}$, annual growth $y$ for fish $i$ at age $j$ from year $k$, cohort $l$ and site $m ; \alpha_{m}^{A}$, random intercept for area $m ; \alpha_{k m}^{Y}$, random extrinsic environmental effect for fishing area $m$ at year $k ; \alpha_{l m}^{C}$, random intercept for cohort $l$ from site $m$

$\beta_{2}$, fixed-effect Age at capture coefficient $q ; b_{1 m}^{A}$, random Age slope for area $m$, correlated with $\alpha_{m}^{A}$ and $b_{2 m}^{A}$; $b_{1 k m}^{Y}$, random Age slope for area $m$ at year $k$, correlated with $\alpha_{k m}^{Y} ; b_{1 l m}^{C}$, random Age slope for area $m$ cohort $l$, correlated with $\alpha_{l m}^{C} ; b_{2 m}^{A}$, random Age at capture slope for area $m$, correlated with $\alpha_{m}^{A}$ and $b_{1 m}^{A}$ 
TABle 3. Continued.

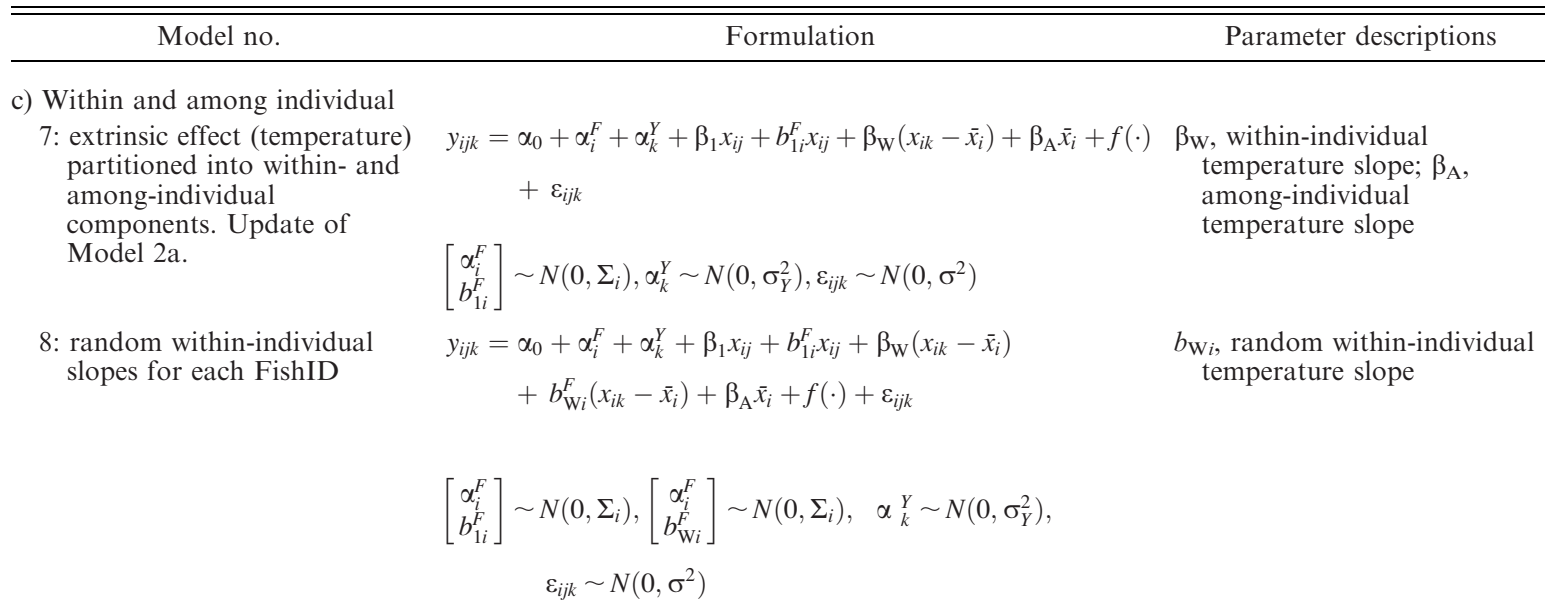

Note: $\mathrm{R}$ code for models is available in the Supplement.

specific differences in age-dependent growth (correlated random slope and intercept). Adding this random Age slope is equivalent to the time-series-based dendrochronological method of detrending each individual's increments to remove age-related trends prior to further analysis (Black 2009), although in our analyses, this information is retained in the model and available for interpretation. Other intrinsic fixed effects such as Sex and its interaction with Age and Age at capture can also be added to Model 1a or $1 \mathrm{~b}$ to explain increment variation.

Fig. 3 compares the proportion of variance explained by intrinsic effects alone in a series of increasingly complex models. The mixed-effects models all explained $\sim 5 \%$ more of the data's total variance $\left(R_{\mathrm{LMM}(\mathrm{c})}^{2}\right)$ compared to the simple linear regression of increment width against Age, most of which was attributed to individual differences in mean increment widths (FishID). Allowing each individual to have a unique growth-age slope (Age $\mid$ FishID) only explained an additional $0.5 \%$ of the total variance, but resulted in a major improvement in $\mathrm{AIC}_{\mathrm{c}}\left(\Delta \mathrm{AIC}_{\mathrm{c}}=541.33\right)$. The most complex model (which included Age $\times \mathrm{Sex}+$ Age at capture) was overall preferred $\left(\Delta \mathrm{AIC}_{\mathrm{c}}=5.12\right)$ and represented the effective partitioning of the sources of variance otherwise attributed to the FishID term alone and thus provides usable information as to why individuals actually differ in their growth rates.

We now approach the formalized hierarchical analysis of fish growth by developing increasingly complex (more inclusive) models of the intrinsic and extrinsic sources of growth variation within areas, using these results to define an optimal model for each area, which we then use to address sources of growth variation across areas, and incorporating within- and among-individual variability through the analysis of individual reaction norms along temperature gradients. Growth model structures are presented in Table 3 and referred to sequentially in the text.

\section{Within-area growth variation}

Hypotheses related to intrinsic drivers of within-area growth variation.-For each fishing area, we developed and compared a series of increasingly complex randomeffect structures that reflected the data's underlying hierarchy (all fitted with the maximal fixed-effects structure of Age $\times$ Sex + Age at capture). Once an optimal random effect structure was selected, we subsequently fitted models of increasing fixed-effect complexity to attribute growth variation into its intrinsic and extrinsic components.

The base within-area model included just a random intercept for FishID (Table 3; model 1a). In this model, the Age fixed effect quantifies the area-average variance associated with the prominent, allometric decline in otolith increment width as an individual got older (e.g., Fig. 2b, c). Model 1a was extended to include a random Age slope for each FishID (Table 3; model 1b). Model $1 \mathrm{~b}$ was preferred over $1 \mathrm{a}$ in all areas (model $1 \mathrm{a}$, $\mathrm{df}=7$; model $1 \mathrm{~b}, \mathrm{df}=9 ; \Delta \mathrm{AIC}_{\mathrm{c}}$ for each area: $\mathrm{NC}, 24.51$; NSW, 86.48; WBS, 1.29; EBS, 396.88; CBS, 19.42; ETAS, 52.51; and WTAS, 26.51). Further, in all areas there was a positive correlation between the random FishID intercept and the Age slope (range 0.25-0.93), indicating that individuals with a larger FishID effect tend to have a more weakly negative Age effect, which together can lead to greater variation in growth across individuals.

A fundamental focus of biochronological studies, regardless of analytical method, is determining how and why growth varies through time. Generally, this variation is assessed on an interannual basis (good vs. poor growth years), with mixed-effect modeling (Weisberg et al. 2010), dendrochronology (Black et al. 2011), or Bayesian hierarchical modeling (Helser et al. 2012). 


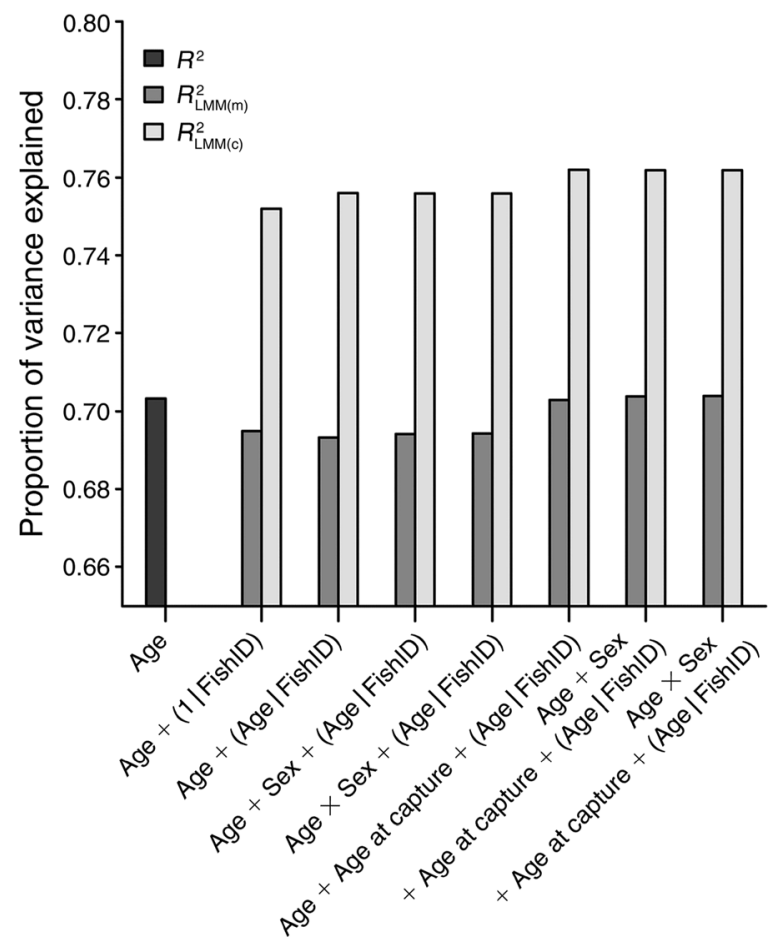

FIG. 3. Proportion of variance explained by a series of increasingly complex intrinsic linear mixed-effects models (LMM) fitted to the pooled tiger flathead data set. Marginal $R^{2}\left(R_{\mathrm{LMM}(\mathrm{m})}^{2}\right)$ is the proportion of variance explained by a mixed model's fixed-effect component, conditional $R^{2}\left(R_{\mathrm{LMM}(\mathrm{c})}^{2}\right)$ is the variance explained by the entire model. Model terms are defined in Table 2. Note that the Age-only model (simple linear regression) is inappropriate for repeated measures data and the $R^{2}$ value only shown to provide context for the other models.

Temporal variation in growth could, however, also reflect and/or be magnified by intrinsic differences in the systematic response of individual cohorts to environmental variability. From a fish perspective, differences in cohort strength may influence competition among sameaged individuals (Whitten et al. 2013), fishery management can impose time-varying selectivity on cohorts (Hagen and Quinn 1991, Sinclair et al. 2002a), or good or poor conditions experienced as a juvenile (growthsurvival hypothesis) may be carried over to later in life and influence future growth and survival (Anderson 1988, Murphy et al. 2013). Similar cohort effects are likely present, and perhaps stronger, in other organisms, such as trees or corals for which biochronologies are developed because individuals cannot move to escape density dependent competition. Furthermore, the strength and direction of age-dependent growth can also vary not only among individuals but across years or cohorts. These varying growth-age relationships may reflect age-dependent responses to environmental variation (e.g., a warm year is good for juveniles but not adults) or that the impacts of competition are differentially manifest for younger and older individuals
(Weatherley and Gill 1987). Furthermore, growth differences may only become evident on decadal rather than annual scales (e.g., Thresher et al. 2007, Cooper et al. 2012).

To test for and quantify these possibilities, we extended the base growth model by adding a Year or Cohort random intercept (Table 3; model 2a, 2b), random Age slopes to these intercepts (model 3a, 3b), both Year and Cohort random intercepts (Table 3; model 4a), or some combination of random Age slopes to both Year and Cohort random intercepts (Table 3; model 4b-4d); see, e.g., Morrongiello et al. (2014). The random Age slopes for Year and Cohort are akin to fitting an age by environment interaction in multiple regression, except that here the Year or Cohort random effect can still be interpreted as overall average yearly or systematic growth even when an interaction is present (Weisberg et al. 2010). Analysis and comparison of models comprised three steps. Firstly, we calculated the intraclass correlation coefficient (ICC), representing the degree of correlation among growth increments from individuals in a Year or Cohort group for model $2 \mathrm{a}$ and $2 \mathrm{~b}$ (intercept-only models to ensure the interpretability of variance components; Goldstein et al. 2002). Secondly, we explored the best models including either a Year or Cohort random intercept (models 2a-3b). Thirdly, we compared the performance of all models (models $1 \mathrm{~b}-4 \mathrm{~d}$ ) and calculated their conditional $R^{2}\left(R_{\mathrm{LMM}(\mathrm{c})}^{2}\right.$ variance explained by fixed and random factors).

There was generally very low levels of amongindividual correlation for a given Year ( ICC $_{\text {Year }}$, $0.002-0.216$ ) or from a given Cohort (ICC Cohort, $0.000-0.245$ ), especially compared to those developed for sessile marine organisms such as molluscs (geoduck, ICC 0.62-0.72; Helser et al. 2012), corals (interseries correlation [analagous to ICC] 0.53-0.65; Carilli et al. 2010), and site-attached marine fish (rockfish, interseries correlation 0.54-0.65; Black 2009; parore, 0.51; Gillanders et al. 2012; rock and longhead flathead, 0.620.64; Coulson et al. 2013; but see western blue groper, 0.112; Rountrey et al. 2014). The low intraclass correlations observed in tiger flathead could be brought about in a number of ways. The spatial resolution around the capture location of each individual fish is coarse (fishing areas up to $93000 \mathrm{~km}^{2}$ or four degrees of latitude in size; Fig. 1a) meaning that only large-scale environmental synchronizers will be readily detected. Small-scale variation in habitat quality or population density that may actually be driving the majority of growth variation (e.g., Lough and Cooper 2011) is subsequently homogenized because we do not have a finer spatial resolution, thus increasing unexplained variation. Furthermore, the model assumes that individual movement is random and independent of environmental variation. Any movement of individuals across their lifetime (up to 50 nautical miles; Rowling 1994) may result in them experiencing a range of microhabitats and thus a reduction in temporal 
TABLE 4. Random effect model selection for each fishing area.

\begin{tabular}{|c|c|c|c|c|c|c|c|c|c|}
\hline Model, by fishing area & $\mathrm{df}$ & $\Delta \mathrm{AIC}_{\mathrm{c}}$ & $\mathrm{LL}$ & $R_{\mathrm{LMM}(\mathrm{c})}^{2}$ & Model, by fishing area & $\mathrm{df}$ & $\Delta \mathrm{AIC}_{\mathrm{c}}$ & $\mathrm{LL}$ & $R_{\mathrm{LMM}(\mathrm{c})}^{2}$ \\
\hline $\mathrm{NC}$ & & & & & CBS & & & & \\
\hline $1 \mathrm{~b}$ & 9 & 37.62 & 424.04 & 0.855 & $1 \mathrm{~b}$ & 9 & $\mathbf{0}$ & -67.59 & 0.647 \\
\hline $2 a$ & 10 & 38.57 & 424.59 & 0.847 & $2 a$ & 10 & 1.03 & -67.09 & 0.652 \\
\hline $2 \mathrm{~b}$ & 10 & 0.73 & 443.52 & 0.869 & $2 \mathrm{~b}$ & 10 & 2.03 & -67.59 & 0.647 \\
\hline $3 \mathrm{a}$ & 12 & 20.43 & 435.74 & 0.843 & $3 a$ & 11 & 3.06 & -67.09 & 0.655 \\
\hline $3 \mathrm{~b}$ & 12 & 1.17 & 445.37 & 0.855 & $3 \mathrm{~b}$ & 12 & 4.87 & -66.98 & 0.647 \\
\hline $4 a$ & 11 & 0 & 444.91 & 0.859 & $4 a$ & 12 & 6.09 & -67.59 & 0.652 \\
\hline $4 \mathrm{~b}$ & 13 & 4.15 & 444.92 & 0.859 & $4 \mathrm{~b}$ & 13 & 6.91 & -66.98 & 0.655 \\
\hline $4 \mathrm{c}$ & 13 & 3.26 & 445.37 & 0.855 & $4 \mathrm{c}$ & 13 & 7.13 & -67.09 & 0.652 \\
\hline $4 d$ & 15 & 7.92 & 445.13 & 0.862 & $4 d$ & 15 & 10.99 & -66.98 & 0.655 \\
\hline NSW & & & & & ETAS & & & & \\
\hline $1 \mathrm{~b}$ & 9 & 470.02 & -51.46 & 0.774 & $1 b$ & 9 & 36.62 & 0.50 & 0.833 \\
\hline $2 a$ & 10 & 32.78 & 168.17 & 0.795 & $2 a$ & 10 & 7.05 & 16.29 & 0.833 \\
\hline $2 \mathrm{~b}$ & 10 & 40.8 & 164.15 & 0.793 & $2 \mathrm{~b}$ & 10 & 36.54 & 1.55 & 0.829 \\
\hline $3 a$ & 12 & 7.8 & 182.68 & 0.810 & $3 a$ & 12 & 0 & 21.83 & 0.829 \\
\hline $3 \mathrm{~b}$ & 12 & 16.7 & 178.23 & 0.796 & $3 \mathrm{~b}$ & 12 & 38.4 & 2.63 & 0.828 \\
\hline $4 a$ & 11 & 23.28 & 173.93 & 0.795 & $4 \mathrm{a}$ & 11 & 9.07 & 16.29 & 0.833 \\
\hline $4 b$ & 13 & 0 & 187.59 & 0.804 & $4 b$ & 13 & 2.02 & 21.83 & 0.829 \\
\hline $4 c$ & 13 & 10.45 & 182.37 & 0.796 & $4 \mathrm{c}$ & 13 & 10.98 & 17.35 & 0.831 \\
\hline $4 d$ & 15 & 12.99 & 183.13 & 0.829 & $4 d$ & 15 & 5.19 & 22.27 & 0.829 \\
\hline WBS & & & & & WTAS & & & & \\
\hline $1 \mathrm{~b}$ & 9 & 4.16 & 11.45 & 0.774 & $1 \mathrm{~b}$ & 9 & 7.06 & -35.89 & 0.770 \\
\hline $2 a$ & 10 & 0 & 14.6 & 0.789 & $2 a$ & 10 & 2.53 & -32.62 & 0.776 \\
\hline $2 b$ & 10 & 5.89 & 11.65 & 0.776 & $2 \mathrm{~b}$ & 10 & 1.02 & -31.86 & 0.771 \\
\hline $3 a$ & 12 & 3.83 & 14.84 & 0.787 & $3 \mathrm{a}$ & 12 & 4.18 & -31.42 & 0.777 \\
\hline $3 \mathrm{~b}$ & 12 & 9.36 & 12.08 & 0.783 & $3 \mathrm{~b}$ & 12 & 3.66 & -31.15 & 0.770 \\
\hline $4 a$ & 11 & 1.58 & 14.89 & 0.791 & $4 \mathrm{a}$ & 11 & 0 & -28.31 & 0.774 \\
\hline $4 \mathrm{~b}$ & 13 & 5.46 & 15.12 & 0.789 & $4 \mathrm{~b}$ & 13 & 0.66 & -30.67 & 0.777 \\
\hline $4 \mathrm{c}$ & 13 & 5.00 & 15.35 & 0.798 & $4 \mathrm{c}$ & 13 & 1.87 & -29.25 & 0.775 \\
\hline $4 d$ & 15 & 27.21 & 6.44 & 0.812 & $4 \mathrm{~d}$ & 15 & 2.31 & -27.43 & 0.779 \\
\hline \multicolumn{10}{|l|}{ EBS } \\
\hline $1 \mathrm{~b}$ & 9 & 1140.52 & -86.75 & 0.738 & & & & & \\
\hline $2 a$ & 10 & 121.89 & 423.56 & 0.755 & & & & & \\
\hline $2 b$ & 10 & 144.9 & 412.06 & 0.728 & & & & & \\
\hline $3 a$ & 12 & 48.81 & 462.11 & 0.758 & & & & & \\
\hline $3 \mathrm{~b}$ & 12 & 48.57 & 462.22 & 0.738 & & & & & \\
\hline $4 \mathrm{a}$ & 11 & 10 & 480.51 & 0.752 & & & & & \\
\hline $4 \mathrm{~b}$ & 13 & 3.76 & 485.63 & 0.756 & & & & & \\
\hline $4 \mathrm{c}$ & 13 & 0 & 487.51 & 0.753 & & & & & \\
\hline $4 d$ & 15 & 71.63 & 453.7 & 0.758 & & & & & \\
\hline
\end{tabular}

Notes: The relative importance of each model was assessed using Akaike's information criterion corrected for small sample sizes $\left(\mathrm{AIC}_{\mathrm{c}}\right)$; best models $\left(\Delta \mathrm{AIC}_{\mathrm{c}}=0\right.$, where $\Delta \mathrm{AIC}_{\mathrm{c}}$ is the difference between each model and the model with the lowest $\left.\mathrm{AIC} \mathrm{C}_{\mathrm{c}}\right)$ are highlighted in bold. Model structures follow Table 2 and all include the fixed effects Age $\times$ Sex + Age at capture. Abbreviations are: $\mathrm{LL}, \log$ likelihood; $R_{\mathrm{LMM}(\mathrm{c})}^{2}$, conditional $R^{2}$ (variance explained by fixed and random factors). For region abbreviations, see Table 1 .

among-individual growth correlation. Such factors have less impact for sessile or strongly site-attached species (Black 2009, Neuheimer et al. 2011, Helser et al. 2012). Other sources of variation that will dampen the strength of among-individual growth correlations and increase the amount of unexplained variance in the model (1$R_{\mathrm{LMM}(\mathrm{c})}^{2}$; Table 4) include measurement error and aging error, although in this instance, these are unlikely to introduce large amounts of variation due to relatively high aging precision (Campana 2001) and large sample sizes.

The best model including a Year random effect was model 2a (just Year intercept) for WBS, CBS, and WTAS, and model $3 \mathrm{a}$ (Year intercept and Age slope) for NC, NSW, EBS, and ETAS (Table 4). Model-extracted patterns in annual growth showed considerable longterm variation within and across areas (Fig. $4 \mathrm{a}-\mathrm{g}$ ). A common feature in the four longest biochronologies (NSW, EBS, ETAS, and WTAS) was a pronounced increase in growth rates from the mid- to late-1990s. There were significant positive pairwise correlations among the Year random-effect conditional modes (best linear unbiased predictors [BLUPs]) for the four longest biochronologies $(r=0.425-0.842)$, and overall the strongest relationships were generally between adjoining areas (Table 5, Fig. 1a). The random Age slope was positively related to the Year random intercept in NSW, EBS, and ETAS (correlation: 0.37, 0.49, and 0.47, respectively) indicating that in good growth years the slope of the growth-age relationship was shallower (i.e., older fish grew proportionally better), whereas in poor growth years it steepened. In NC, this relationship was negative (correlation, -0.36 ) indicating that younger fish grew proportionally better in good growth years and less 

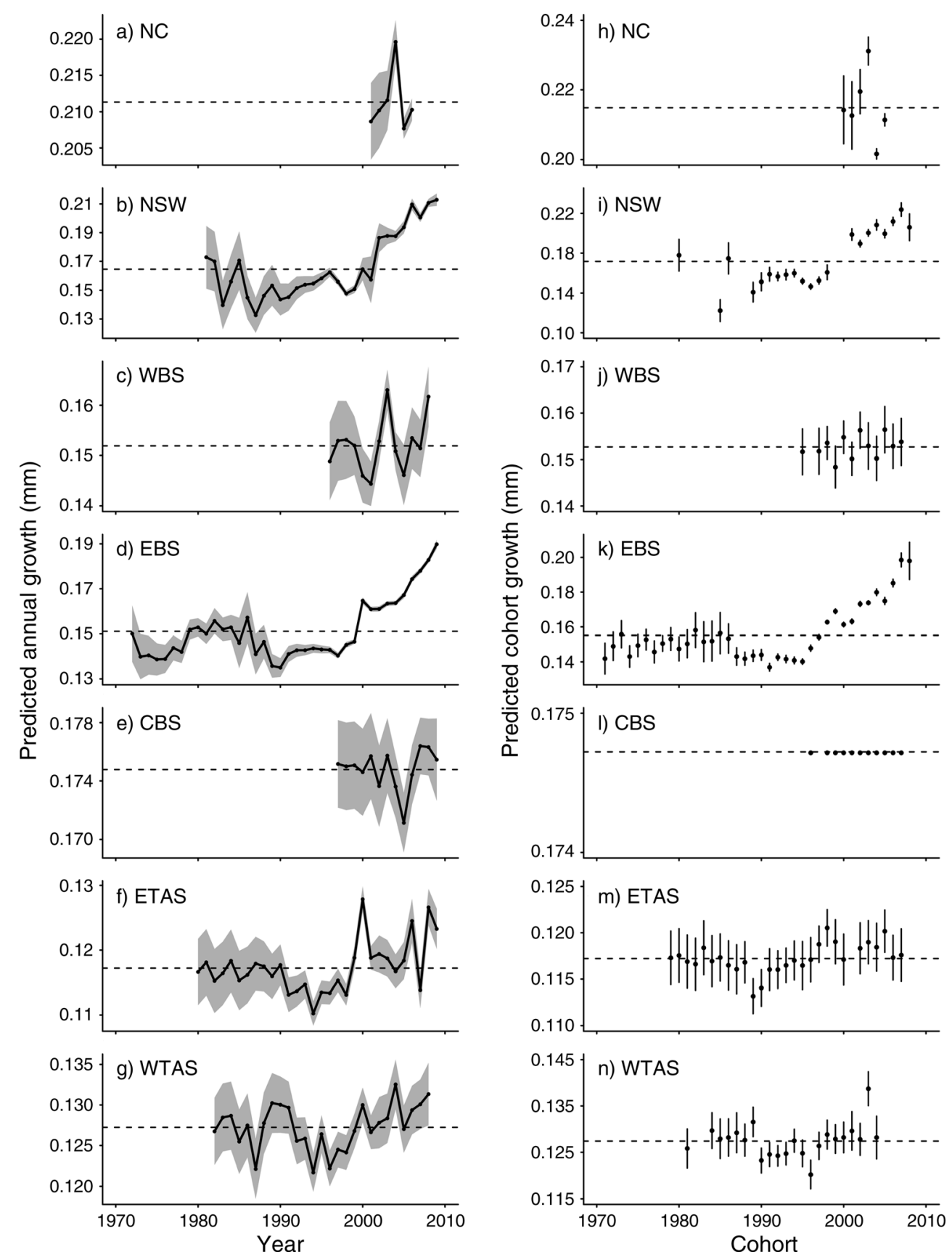

FIG. 4. Predicted time-dependent average growth variation (after accounting for intrinsic effects) for tiger flathead across seven fishing areas back-transformed to the original scale. (a-g) Annual growth variation represented by Year random-effect conditional modes (best linear unbiased predictors [BLUPs] \pm SE). (h-n) Systematic cohort-specific growth variation represented Cohort random-effect conditional modes (BLUPs $\pm \mathrm{SE}$ ). Dashed lines in each panel represent long-term average growth (fixed-effect intercept for each zone's model). Note different scales on the $y$-axes.

so in poor years (vice versa for older fish). This important ecological inference is not possible with traditional analytical techniques.

A Cohort random intercept only model (model 2b) was best for NC, WBS, CBS, ETAS, and WTAS, while the addition of an Age random slope for the Cohort intercept (model 3b) was best for NSW and EBS (Table
4). There was less evidence of directional variation in Cohort-specific growth (Fig. 4h-n), although in all areas, there were cohorts characterized by systematic low or high growth across individuals' lifetimes. Prominent features in both NSW and EBS were depressed growth in individuals spawned in the 1990s and elevated growth in those spawned in the 2000s. 
TABLE 5. Pearson's correlation coefficients $(r)$ for pairwise comparisons of area-specific interannual growth variation $(P$ values in parentheses).

\begin{tabular}{|c|c|c|c|c|c|c|c|}
\hline Fishing area & $\mathrm{NC}$ & NSW & WBS & EBS & CBS & ETAS & $\overline{\text { WTAS }}$ \\
\hline $\mathrm{NC}$ & 1 & & & & & & \\
\hline NSW & $\begin{array}{c}0.132 \\
(0.803)\end{array}$ & 1 & & & & & \\
\hline WBS & $\begin{array}{c}0.243 \\
(0.643)\end{array}$ & $\begin{array}{c}0.396 \\
(0.180)\end{array}$ & 1 & & & & \\
\hline EBS & $\begin{array}{r}-0.120 \\
(0.821)\end{array}$ & $\begin{array}{c}0.842 \\
(<0.001)\end{array}$ & $\begin{array}{c}0.217 \\
(0.476)\end{array}$ & 1 & & & \\
\hline CBS & $\begin{array}{c}0.086 \\
(0.871)\end{array}$ & $\begin{array}{c}-0.043 \\
(0.89)\end{array}$ & $\begin{array}{c}0.451 \\
(0.142)\end{array}$ & $\begin{array}{c}0.127 \\
(0.680)\end{array}$ & 1 & & \\
\hline ETAS & $\begin{array}{c}-0.399 \\
(0.433)\end{array}$ & $\begin{array}{c}0.491 \\
(0.007)\end{array}$ & $\begin{array}{c}0.136 \\
(0.657)\end{array}$ & $\begin{array}{c}0.640 \\
(<0.001)\end{array}$ & $\begin{array}{c}0.046 \\
(0.881)\end{array}$ & 1 & \\
\hline WTAS & $\begin{array}{c}0.950 \\
(0.004)\end{array}$ & $\begin{array}{c}0.425 \\
(0.027)\end{array}$ & $\begin{array}{c}0.240 \\
(0.429)\end{array}$ & $\begin{array}{c}0.497 \\
(0.008)\end{array}$ & $\begin{array}{c}0.070 \\
(0.828)\end{array}$ & $\begin{array}{c}0.514 \\
(0.006)\end{array}$ & 1 \\
\hline
\end{tabular}

Notes: Significant correlations $(P<0.05)$ are highlighted in bold. Best linear unbiased predictors (BLUPs) are presented in Fig. 4. See Table 4 for definitions of abbreviations.

There was also a positive correlation between the random Cohort intercept and Age slope in both these areas (NSW, 0.52; EBS, 0.80) This recent increase in cohort-specific growth coincides with recent strong, but variable, recruitment for the eastern tiger flathead fishery (Klaer 2010) and may indicate a link between the two (see Murphy et al. [2013] for empirical example).

There was considerable diversity in the best models selected for each area, and despite the low levels of growth synchrony among individuals, the best models from six of the seven areas included a Year and/or Cohort random intercept (Table 4; see Appendix E: Text E1 for description). These models overall were a better fit to the data and explained between $64.7 \%$ and $85.9 \%$ of the total area-specific growth variance (Table 4). CBS models consistently explained the lowest level of data variation suggesting that other model structures or covariates not captured here may be important. Overall, our results indicate that individuals are not necessarily displaying a uniform growth signal to within-area environmental variation. This result is perhaps not surprising given the underlying sampling protocol and the fact that individual growth is very complex and dependent on a wide range of processes operating at different scales. The latter point is supported by the presence of random Age slopes for either Year or Cohort in four of the seven areas, which indicate that ontogenetic interactions with the environment are an important component of an individual's lifetime growth trajectory. Nonetheless, we did detect evidence of region-wide growth synchrony, which we will address in the across-area section.

To quantify and specifically test for explicit intrinsic effects on growth rates at the within-fishing-area level, we fitted six models of increasing fixed-effect complexity to each area using the optimal random-effects structure (from Table 4). The simplest included Annual growth being log-linearly dependent on Age, with as necessary, random Age slopes for each FishID, Year, and Cohort random intercept. To this we added two additional factors: Sex and, additively, Age at capture.
The importance of explicit intrinsic effects on annual growth variation differed across areas (Appendix E: Table E1). As expected, growth was negatively related to Age in all areas. There was also an indication of sexspecific growth differences in EBS, ETAS, and WTAS (males generally grew slower than females), with this relationship varying with Age in EBS and ETAS, i.e., females grew faster than males over some age classes, but not others (Table 6a; Appendix E: Fig. E1). Individual growth rates were negatively related to Age at capture in five of the seven areas and positively related in one (NC; Table 6a; Appendix E: Fig. E1), suggesting that growth rate-based selectivity occurs in parts of this species' range, whereby faster-growing individuals generally do not reach the same older ages as slowergrowing individuals. Several possible explanations for this effect have been suggested in general, including lifehistory trade-offs between growth rate, sexual maturity, and longevity (Heino et al. 2002), higher vulnerability of fast growers to fishery activities as these individuals attain a catchable size at a younger age (Rosa Lee phenomenon, Ricker 1969; fishery induced evolution, Heino and Godo 2002, Jorgensen et al. 2007; see Hagen and Quinn [1991] and Sinclair et al. [2002a] for otolithbased growth selectivity examples), or because faster growers have intrinsically greater energy requirements and feeding activity rates (Werner and Anholt 1993) or are bolder and thus are more likely to encounter fishing gear (Biro and Post 2008). No Age at capture and Annual growth relationship, however, was evident in NSW, and a positive relationship was present in NC, two areas that have historically experienced high levels of commercial fishing (Tilzey and Rowling 2001, Klaer 2004). For NSW, this could mean that any fisheryrelated selectivity has already stabilized, and for NC, the lack of any fish older than six years in our samples may have influenced results or could in itself reflect a fishery or environmental impact. More generally, the patterns observed may represent differences in sampling or gear selectivity across fishing areas. Regardless of the underpinning mechanism, including an Age at capture 
TABle 6. Parameter estimates (with SE) and test statistic $t$ for best models from each fishing area.

\begin{tabular}{|c|c|c|c|c|c|c|}
\hline \multirow[b]{2}{*}{ Model and parameter } & \multicolumn{2}{|l|}{$\mathrm{NC}$} & \multicolumn{2}{|l|}{ NSW } & \multicolumn{2}{|c|}{ WBS } \\
\hline & Estimate (SE) & $t$ & Estimate (SE) & $t$ & Estimate (SE) & $t$ \\
\hline a) Intrinsic-effects model & & & & & & \\
\hline $\begin{array}{l}\text { Intercept } \\
\text { Age } \\
\text { Age at capture } \\
\text { Sex (male) } \\
\text { Age } \times \text { Sex }\end{array}$ & $\begin{array}{r}-1.567(0.009) \\
-0.667(0.035) \\
0.102(0.037)\end{array}$ & $\begin{array}{r}53.49 \\
18.97 \\
2.79\end{array}$ & $\begin{array}{l}-1.814(0.034) \\
-0.907(0.028)\end{array}$ & $\begin{array}{l}53.84 \\
33.92\end{array}$ & $\begin{array}{l}-1.884(0.024) \\
-0.812(0.041) \\
-0.110(0.049)\end{array}$ & $\begin{array}{l}77.44 \\
19.741 \\
2.22\end{array}$ \\
\hline $\begin{array}{l}\text { b) Temporal trend model } \\
\text { Year }\end{array}$ & & & $0.023(0.002)$ & 11.68 & $0.029(0.010)$ & 3.03 \\
\hline $\begin{array}{l}\text { c) Temperature model } \\
\text { Bottom temperature } \\
\text { Bottom temperature }\end{array}$ & $\begin{array}{l}-0.091(0.030) \\
-0.435(0.269)\end{array}$ & $\begin{array}{l}3.05 \\
1.62\end{array}$ & $0.345(0.123)$ & 2.80 & $-0.144(0.082)$ & 1.75 \\
\hline $\begin{array}{c}\text { d) Within- vs. among-individua } \\
\beta_{\mathrm{W}} \text { (within-individual effect) } \\
\beta_{\mathrm{A}} \text { (among-individual effect) }\end{array}$ & $\begin{array}{l}\text { iation } \\
-0.105(0.052) \\
-0.097(0.111)\end{array}$ & $\begin{array}{l}2.01 \\
0.87\end{array}$ & $\begin{array}{l}0.286(0.135) \\
0.375(0.129)\end{array}$ & $\begin{array}{l}2.12 \\
2.90\end{array}$ & $\begin{array}{r}-0.221(0.076) \\
0.030(0.118)\end{array}$ & $\begin{array}{l}2.92 \\
0.26\end{array}$ \\
\hline
\end{tabular}

term in biochronology analyses helps to identify any ecologically and evolutionarily relevant growth-based selectivity that may occur in a species and corrects for biases that may exist in the underlying sampling regime that would otherwise compromise analyses (Morrongiello et al. 2012).

Hypotheses related to extrinsic drivers of within-area growth variation.-We tested for temporal directionality in interannual and cohort-specific growth by adding a linear Year covariate as a fixed effect to the optimal intrinsic-effect model (Appendix E: Table E1). The addition of a temporal trend improved model performance in five of seven areas (Appendix E: Table E2). While the addition of a Year term had little effect on the amount of overall variance explained by each model $\left(R_{\mathrm{LMM}(\mathrm{c})}^{2}\right.$ in Appendix E: Table E2), it did result in an improvement in variance explained by fixed effects $\left(R_{\mathrm{LMM}(\mathrm{m})}^{2}\right)$ and make the model's overall fit more easily interpretable through the explicit attribution of growth variation to a driver. Specifically, after taking into account intrinsic factors, annual growth increased in NSW, WBS, EBS, ETAS, and WTAS (Table 6b, Fig. 4) from between $0.70 \%$ and $2.50 \%$ per year over the study period. These increases are consistent with results from biochronologies developed for four other shallow water species in southeast Australia (Thresher et al. 2007, Neuheimer et al. 2011), indicating that this is a regional, rather than species or population-specific, response. The two flathead biochronologies that did not display a temporal trend were the shortest in length (NC, $6 \mathrm{yr}$; CBS, $13 \mathrm{yr}$ ), and hence may not have been long enough to detect the trend. To investigate possible environmental drivers of these temporal growth trends and residual extrinsic variation, we replaced the Year fixed effect with just Temperature (both as linear and quadratic terms) for the full growth record, and then Temperature (linear and quadratic) and Abundance (including an interaction with Temperature to test for fishing and environmental synergies; Planque et al. 2010) for the restricted data set. Both extrinsic parameters were crossed with Age to allow for age-dependent responses to environmental variation.

Interannual variability in tiger flathead growth correlated with annual bottom Temperature in most areas, but we found no evidence of these patterns being age dependent. Again, while the addition of another fixed effect increased model complexity but made little difference to overall levels of explained variance, it did improve the model's biological interpretability as interannual growth variation could now be interpreted in light of temperature changes. Based on the full, longer-term, data set, the best models for NSW, WBS, EBS, ETAS, and WTAS included a linear Temperature parameter, for NC it included a quadratic Temperature parameter, while for CBS, the best model included just intrinsic effects (Appendix E: Table E3). The magnitude and direction of temperature effects varied latitudinally (Fig. 5). The southern, and thus cooler, areas experienced modest increases in Annual growth with annual temperature $\left(+7.29 \%\right.$ per ${ }^{\circ} \mathrm{C}$ in WTAS and $+7.74 \%$ per ${ }^{\circ} \mathrm{C}$ in ETAS). In more northward areas, increases in temperature of similar magnitude to those farther south coincided with annual growth rates increasing by $14.29 \%$ per ${ }^{\circ} \mathrm{C}$ in EBS and $41.21 \%$ per ${ }^{\circ} \mathrm{C}$ in NSW, but declined by $13.40 \%$ per ${ }^{\circ} \mathrm{C}$ in WBS (the latter had wide confidence intervals encompassing zero). Finally, in the northernmost area (NC), growth rate initially increased up to $\sim 16.3^{\circ} \mathrm{C}$, whereafter it declined (Table 6c, Fig. 5). Extrinsic-effects models developed using the restricted data set were qualitatively similar to those from the full 
TABLE 6. Extended.

\begin{tabular}{|c|c|c|c|c|c|c|c|}
\hline \multicolumn{2}{|c|}{ EBS } & \multicolumn{2}{|c|}{ CBS } & \multicolumn{2}{|c|}{ ETAS } & \multicolumn{2}{|c|}{ WTAS } \\
\hline Estimate (SE) & $t$ & Estimate (SE) & $t$ & Estimate (SE) & $t$ & Estimate (SE) & $t$ \\
\hline $\begin{array}{l}-1.855(0.015) \\
-0.757(0.011) \\
-0.021(0.008) \\
-0.036(0.005) \\
-0.031(0.010)\end{array}$ & $\begin{array}{c}124.67 \\
65.94 \\
2.68 \\
7.2 \\
2.97\end{array}$ & $\begin{array}{l}-1.748(0.010) \\
-0.699(0.021) \\
-0.116(0.027)\end{array}$ & $\begin{array}{r}174.14 \\
32.91 \\
4.28\end{array}$ & $\begin{array}{l}-2.145(0.013) \\
-0.759(0.017) \\
-0.107(0.018) \\
-0.040(0.015) \\
-0.066(0.021)\end{array}$ & $\begin{array}{r}170.13 \\
44.17 \\
6.02 \\
2.73 \\
3.19\end{array}$ & $\begin{array}{l}-2.061(0.014) \\
-0.730(0.014) \\
-0.128(00025) \\
-0.050(0.014)\end{array}$ & $\begin{array}{r}144.86 \\
52.27 \\
5.19 \\
3.55\end{array}$ \\
\hline $0.007(0.001)$ & 6.95 & & & $0.008(0.002)$ & 3.91 & $0.007(0.003)$ & 2.77 \\
\hline $0.138(0.043)$ & 3.25 & & & $0.077(0.032)$ & 2.44 & $0.070(0.029)$ & 2.41 \\
\hline $\begin{array}{r}-0.102(0.033) \\
0.411(0.036)\end{array}$ & $\begin{array}{r}3.05 \\
11.49\end{array}$ & $\begin{array}{l}0.005(0.040) \\
0.122(0.217)\end{array}$ & $\begin{array}{l}0.12 \\
0.56\end{array}$ & $\begin{array}{r}-0.0002(0.024) \\
0.373(0.045)\end{array}$ & $\begin{array}{l}0.01 \\
8.31\end{array}$ & $\begin{array}{l}0.070(0.030) \\
0.065(0.130)\end{array}$ & $\begin{array}{l}2.35 \\
0.50\end{array}$ \\
\hline
\end{tabular}

data set for the majority of areas (Appendix E: Table E4, Text E2). The general lack of detectable and consistent Abundance effects (or any interactions with Temperature) on growth rates could result from ecological factors (weak intraspecific competition for resources, possibly coupled to low overall abundances) or more likely, the limited sensitivity of fisheries-derived CPUE indices as estimators of population density.

\section{Across-area variation in annual growth}

Models 1a-4d (and their fixed-effect derivations) are not spatially explicit; they neither integrate nor test hypotheses regarding factors that span the species' range (e.g., Leites et al. 2012). Such spatial analyses are difficult to perform using traditional dendrochronological and some age-specific regression approaches because of dimensionless indices or the assumption of a common climatic response (Lapointe-Garant et al. 2010, Morrongiello et al. 2012). To test hypotheses relevant to across-region drivers of growth variation, we included in model 5 area-specific random intercepts (Area) for Year and Cohort (Table 3). The Area intercept induces correlation among Years and Cohorts within an area and allows drawing spatial and temporal inferences about growth variation without having to estimate spatial autocorrelation structures (Brown et al. 2011). We also explored whether there was variation in amongarea Age and Age at capture and among Year and Cohort Age fixed-effect slopes by including these as random slopes for each area. In all, 16 models of increasing random-effect complexity were compared. Fixed-effect structures initially included the terms Age, Sex, and their interaction and Age at capture. The best performing random-effects structure that spanned the species' entire range was the most complex (Appendix F: Table F1) and included random Age slopes for FishID, Area, Year, and Cohort and random Age at capture slopes for Area (shown in Table 3 as Model 6).
Temperature varies over space and time (Fig. 1a, b). Consistent spatial differences in long-term temperature averages will result in concordant variability in prey quality and quantity, competition and predation, and potential differential selectivity. These may result in an underlying, geographically related gradient in average growth. Short-term departures from these long-term temperature averages capture environmental stochasticity and can be reflected in an individual's interannual

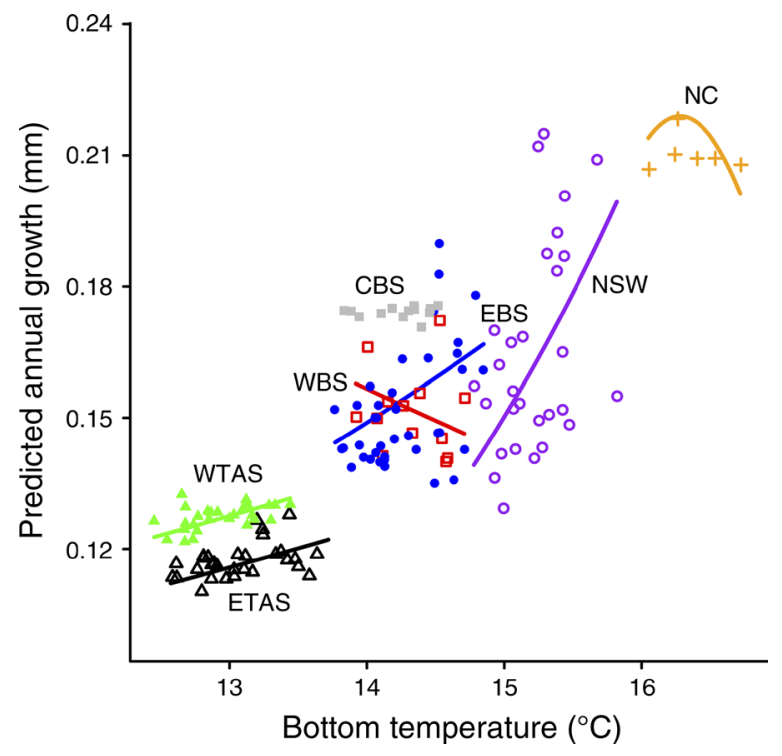

FIG. 5. Predicted annual growth of two-year-old male tiger flathead (Age at capture held at mean value) by bottom temperature for each area. Points are Year random-effect conditional modes (BLUPs) generated from optimal intrinsiceffect models (Appendix D: Table D1) and represent average extrinsic growth variation. Solid triangles represent WTAS; open triangles represent ETAS; solid circles represent EBS; solid squares represent CBS; open squares represent WBS; open circles represent NSW; crosses represent NC. See Fig. 1 for definitions of abbreviations. Note that temperature was not included in the best model for CBS. 
TABle 7. Parameter estimates and test statistics for best model describing across-area tiger flathead growth.

\begin{tabular}{lccr}
\hline \hline \multicolumn{1}{c}{ Parameter } & Estimate & SE & \multicolumn{1}{c}{$t$} \\
\hline Intercept & -1.854 & 0.278 & 6.68 \\
Age & -0.771 & 0.076 & 10.18 \\
Age at capture & -0.036 & 0.204 & 0.18 \\
Sex (male) & -0.025 & 0.004 & 6.92 \\
Age $\times$ Sex & -0.018 & 0.007 & 2.58 \\
AvTemp & 0.148 & 0.030 & 4.87 \\
TempAnom & 0.096 & 0.022 & 4.31 \\
AvTemp $\times$ TempAnom & 0.053 & 0.026 & 2.08
\end{tabular}

growth plasticity. To explore the relative importance of these spatial and temporal components of Temperature, we first calculated area-specific temperature normals (average) over the period 1970-2011 (AvTemp), and then within-area temperature anomalies (TempAnom) were calculated as the difference between a given year's Temperature and AvTemp (Table 2). Temperaturedependent spatial and temporal patterns in flathead growth were explicitly modelled by adding various combinations of AvTemp, TempAnom, and their interaction and quadratic terms as fixed effects to model 6. AvTemp and its quadratic polynomial explore drivers of systematic spatial-growth variation and describe the spatial pattern evident in Fig. 5. TempAnom and its quadratic investigate whether growth is impacted by departures of short-term climate from its area-specific long-term normal. The interaction between AvTemp and TempAnom investigates whether areas differ in their growth response to similar magnitude departures of short-term temperature from long-term temperature.

The best performing fixed-effect derivation of model 6 included terms for Age $\times$ Sex, Age at capture, and AvTemp $\times$ TempAnom (Appendix F: Table F2). Overall, growth declined with age, the rate of which was steeper for males than for females (Table 7, Fig. 6a). Age-dependent growth rates also varied geographically (random Age slopes for each Area; Fig. 6b). Across all areas, growth was not strongly related to Age at capture (Table 7, Fig. 6c), but the slope of this relationship differed considerably among areas (Fig. 6d), reemphasizing the need to include this term in biochronological analyses.

Integrated across areas, tiger flathead growth response to short-term temperature variation was dependent on an area's long-term temperature normal (Table 7). Results are consistent with inferences from the within-area analyses. Growth was lowest when long-
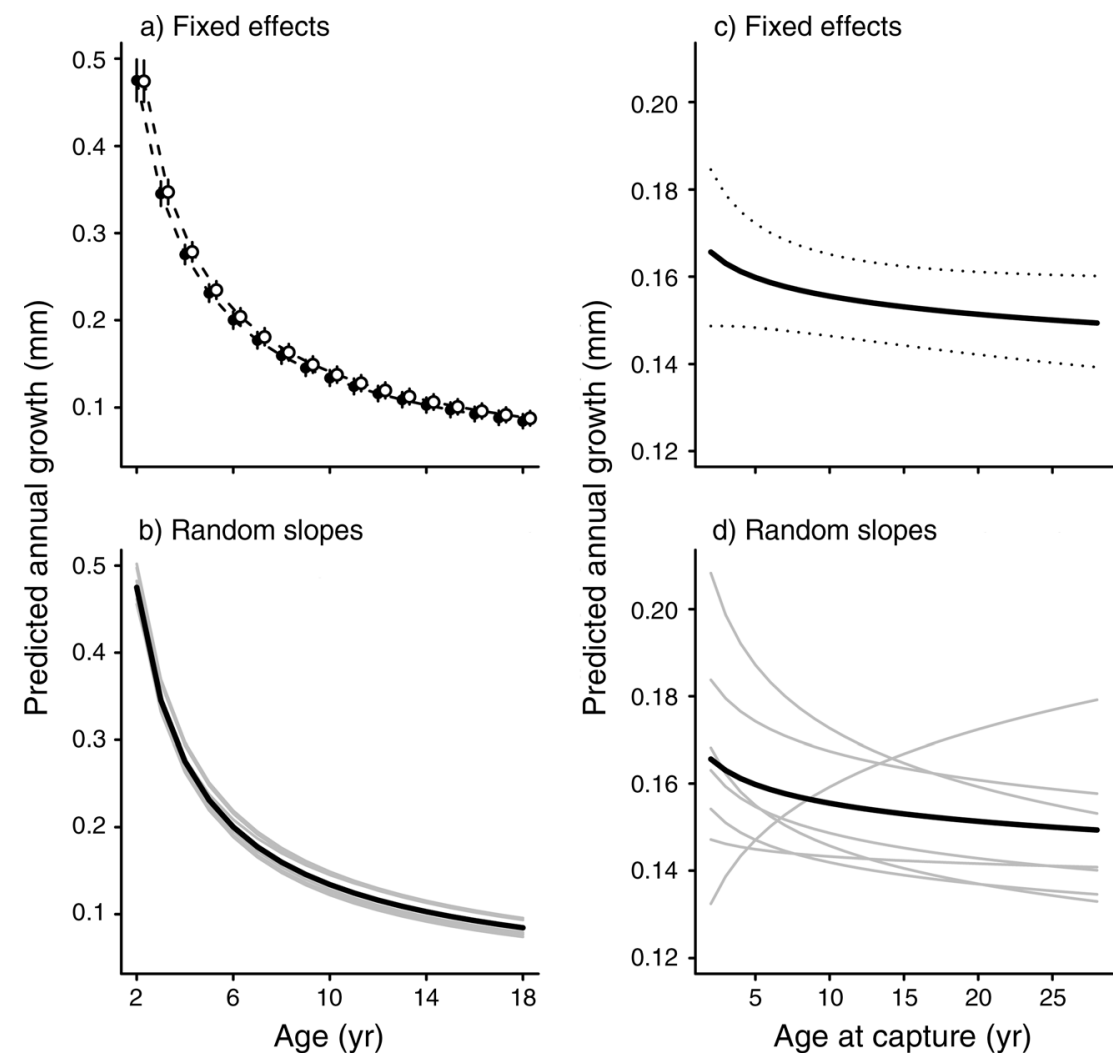

FIG. 6. Predicted annual growth variation in tiger flathead across all fishing areas back-transformed to the original scale. (a) Age- and sex-dependent trends (mean with $95 \%$ CI) for males (solid circle) and females (open circles); females are offset on the $x$ axis for clarity; (b) among-area (gray lines) variation in the growth-age relationship about the species' average (black line); (c) species' age-at-capture trend (mean with $95 \%$ CI); (d) among-area (gray lines) variation in the growth-age-at-capture relationship about the species' average (black line). 
term temperature averages were coolest (more southerly), and here, short-term positive temperature anomalies did little to increase growth (Fig. 7). For warmer average conditions, growth increased and began to more positively respond to warmer years over the short term. Finally, growth was highest at the warmest long-term average temperatures and under these conditions responded strongly to positive short-term temperature anomalies. The across area model did not, however, adequately fit the data from NC (compare direction of $\mathrm{NC}$ slope in Fig. 5 with the $16.5^{\circ} \mathrm{C}$ slope in Fig. 7), likely due to the relatively few years of data available for this area and the limitations of exploring just linear terms.

\section{Within vs. among individual variation}

The expression of phenotypic traits, like growth, varies within and among individuals (adaptively, nonadaptively, or neither) depending on the interplay between genetics and the environmental conditions experienced (Pigliucci 2005). Models 1-6 considered fishing area- and species-level growth responses to environmental variation. However, the nature of individual-level plasticity cannot always be easily inferred from population-centric models, as they can obscure individual variability in responses and hence the degree of trait heterogeneity in a population (Nussey et al. 2007, Clutton-Brock and Sheldon 2010). Importantly, inference at one level of biological organization (e.g., the population) is dependent on processes operating at lower levels of organization (e.g., among and within individuals). Exploring this hierarchy can therefore provide valuable evolutionary context to ecological insights.

Data sets collected from wild animals, such as otolith increment measurements, also pose a problem to studying individual-level variation, because we cannot choose the level of a predictor variable (e.g., temperature) at which we measure a trait (e.g., growth; van de Pol and Wright 2009). Not all tiger flathead are exposed to the same conditions; fish spawned in earlier years, for example, experienced on average cooler conditions than those spawned more recently (Fig. 1b). The random FishID intercepts in models 1-6 account for amongindividual differences in average growth, but do not take into account among-individual differences in temperature experienced. Consequently, the observed population-level temperature relationships (Fig. 5) could derive from either within-individual phenotypic plasticity (reaction norms) or among-individual effects in which fish that experienced on average warmer waters throughout their lives have higher (or lower) growth rates due to genetic or nongenetic effects or a combination of both. Furthermore, opposing within- and among-individual effects can even cancel each other out, as for example when physiology supports a positive growth-temperature relationship (within individuals), but food availability declines in

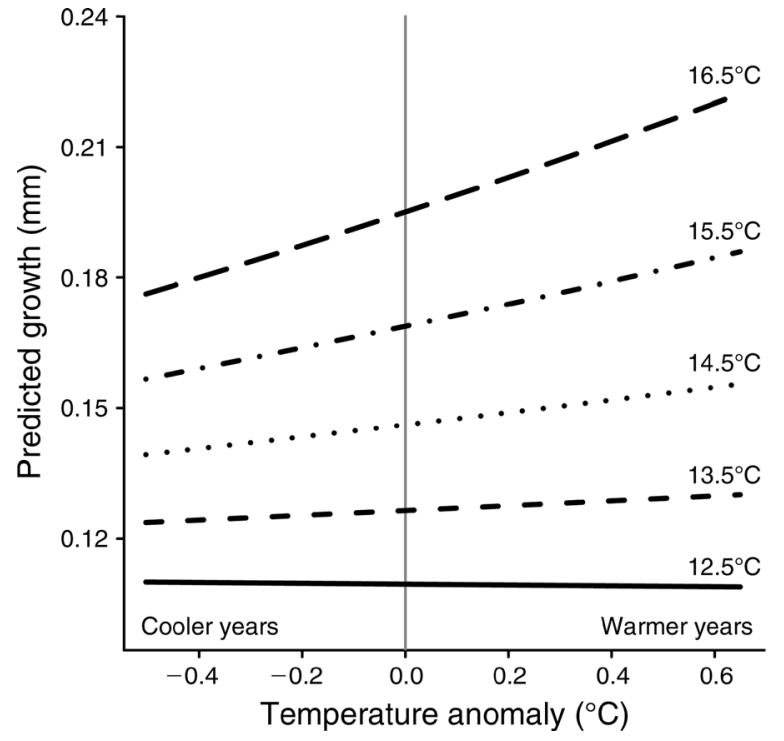

FIG. 7. Interaction plot of predicted regional variation in tiger flathead annual growth as a function of five long-term average temperature values $\left(12.5-16.5^{\circ} \mathrm{C}\right.$; AvTemp) and withinarea short-term temperature variation ( $x$-axis temperature anomaly, TempAnom), back-transformed to the original scale with other covariates held at their mean values.

warmer conditions resulting in lower average growth (among individuals).

We used a similar technique to that employed for the across-area analyses (called within-subject centering by van de Pol and Wright [2009]) to calculate an average temperature experienced by individuals across their lifetime $\left(\bar{x}_{i}\right)$ and the deviation of each annual temperature from this mean $\left(x_{i k}-\bar{x}_{i}\right.$; Table 2$)$. These two new predictor variables were fitted in model 7 (Table 3); their coefficients provide, respectively, an estimate of how growth systematically varies across average lifetime conditions (among-individual slope $\beta_{A}$ ) and an estimate of the average growth phenotypic plasticity present within an area (within-individual slope $\beta_{W}$; see van de Pol and Wright [2009] for a thorough discussion of the method). Model 7 can be expanded to include individual-specific differences in within-individual temperature slopes (random $\beta_{W}$ for FishID), thus facilitating an exploration of among-individual variation in individual reaction norms (Table 3; model 8).

Model selection and results summaries are presented in Appendix G: Text G1, and within- and amongindividual growth variation patterns are illustrated in Fig. 8. In the low-latitude NC, we identified a negative, curvilinear population-level growth response to increasing temperature (Fig. 8a), which was a consequence primarily of within-individual phenotypic plasticity. Moving poleward, the strong positive area-level growth response in NSW can be attributed to similar levels of within-individual phenotypic plasticity and amongindividual growth variation, where those fish that were alive in warmer years had higher average growth rates 

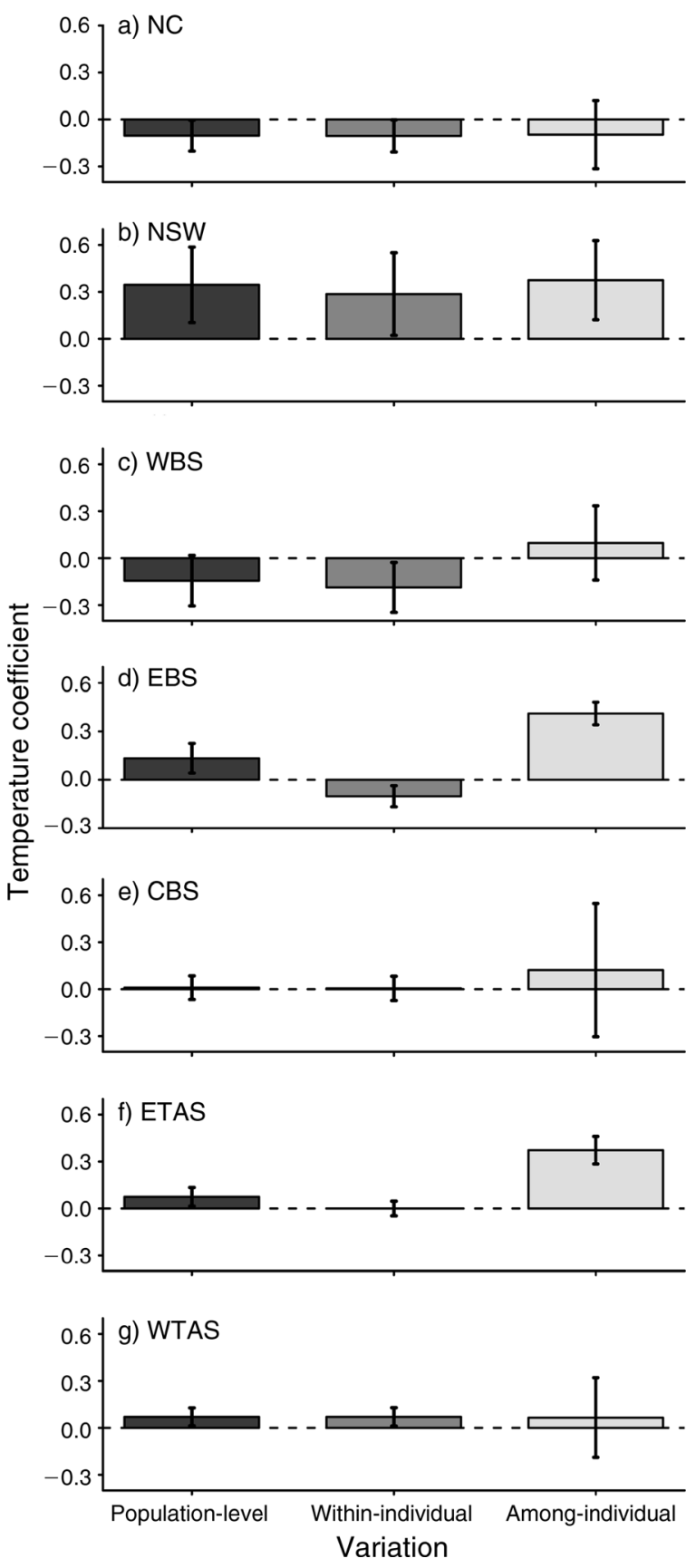

FIG. 8. Predicted population-level, within-individual, and among-individual variation in bottom temperature coefficients (mean with 95\% CI) for log-transformed annual growth. Note that a linear temperature coefficient is presented for $\mathrm{NC}$ to aid interpretation (best model includes Temperature + Temperature $^{2}$ ). See Fig. 1 for definitions of abbreviations.

(Fig. 8b). The weak area-level response to temperature in WBS masked evidence of much stronger negative average phenotypic plasticity, which was likely cancelled out by slightly positive among-individual variation (Fig. 8c). In EBS and ETAS, within- and among-individual variation partially cancelled each other out with the positive area-level growth response underestimating substantial among-individual growth variation related to average experienced temperatures (Fig. 8d,f). WTAS fish showed an inverse pattern to those in $\mathrm{NC}$ with the majority of the population-level growth response attributable to within-individual phenotypic plasticity (Fig. 8g). No clear patterns were evident in CBS (Fig. 8e). There was little evidence of temporal patterns in within individual reaction norms (see Appendix G: Text G2 for results and discussion).

\section{Synthesis and conclusions}

Hierarchically structured biochronologies are widely available in ecological and ecophysiological contexts, ranging from elemental and morphological time-series in ibex horns (Büntgen et al. 2014) and whale ear plugs (Trumble et al. 2013) to classic tree-ring-based dendrochronology (Cook and Kairiukstis 1990). The information that can be extracted from such chronologies depends on the fidelity of the proxy and the extent to which parameters of interest can be separated from the influence of other factors. In traditional climate-oriented biochronological studies, this separation often takes the form of arbitrarily excluding from the analysis complacent individuals in order to better describe the climate signal of interest (D'Arrigo et al. 2006) or by using information from only situations that a priori exclude the effects of confounding variables and maximize sensitivity, e.g., examining tree rings only from specimens in high-elevation environments in order to isolate the effects of temperature of growth (Cook et al. 2000). While such approaches have obvious merit in climatic hindcasting where a strong proxy signal is desired, they limit ecological inference due to often small and/or nonrepresentative (and thus biased) samples (NehrbassAhles et al. 2014), averaging across levels of biological hierarchy, and the exclusion from analysis of important components of growth variation (Carrer and Urbinati 2004, Morrongiello et al. 2012).

In a similar vein, the majority of ecologically focused biochronological studies on fishes have investigated extrinsic, population-level sources of variation, such as water temperature, with the effects of intrinsic, individual age-, behaviorally, or genetically dependent variation either explicitly detrended and averaged out (traditional dendrochronology; Black 2009) or excluded by analyzing only a limited range of ages (age-specific regression; Thresher et al. 2007, Neuheimer et al. 2011). Mollusc and coral-based studies also largely ignore intrinsic sources of growth variation (Helama et al. 2006, Carilli et al. 2010, Cooper et al. 2012). While a focus on extrinsic drivers has provided valuable insight into how such organisms respond to changing environmental conditions over decadal to centenary time periods, they exclude from consideration potentially valuable intrinsic-level information encoded in hard parts (Pilling et al. 2002, Brannon et al. 2004) and within- and among-individual phenotypic and genetic 
variation (Nussey et al. 2007, Biro and Post 2008, van de Pol and Wright 2009). Extrinsic- and intrinsic-level information, as well as the interaction between the two, is integral to understanding how populations and species have and will respond to changing environmental conditions, because it is the individual that experiences and interacts with its environment (Clutton-Brock and Sheldon 2010).

We examine an alternative model-based approach that utilizes the full hierarchical structure of biochronological data and that allows exploring, parameterizing, and quantifying underappreciated intrinsic effects, as well as more familiar extrinsic effects, on growth rates. Models could be developed for other hierarchically structured proxies, i.e., age-dependent variability in otolith isotopic composition, as well as other situations where the underlying data is hierarchical, e.g., life history parameters, Clutton-Brock and Sheldon (2010); dendrochronology, Leites et al. (2012); animal behavior, Dingemanse and Dochtermann (2013); and fisheries, Hagen and Quinn (1991), Sinclair et al. (2002a). Specifically, we develop a series of nested spatially and temporally explicit models that allow for the quantitative comparison of within- and among-individual and within- and among-area growth rates, analyses that are not possible using techniques that have their genesis in the hindcasting of past environmental conditions.

Not surprisingly in the case of tiger flathead, and, likely, otoliths in general, the majority of the variance in annual growth rates as proxied in growth increments is accounted for by allometrically declining age-dependent growth. Adding individual variability (FishID) to Age only increased the amount of variance accounted for by between $0.8 \%$ and $8.5 \%$, and even our most complex models explained only a small amount of additional variance (between $64.7 \%$ and $85.9 \%$ of the total areaspecific variance; Table 4). However, these more complex models were a better fit to the data based on $\mathrm{AIC}_{\mathrm{c}}$. Their value comes not from explaining more of the variance, but rather by generating testable hypotheses and partitioning the variance in, for example, FishID or Year, among biologically interpretable components. Likewise, selection can act on minor aspects of trait variation, and these models are more sensitive to detecting and attributing any such changes. Examples gleaned from our analyses include responses to good and bad years that differ among age groups, Age at capture effects in six of the seven fishing areas that unless accounted for could result in biased results due to selective sampling, distinguishing between Cohort and Year effects within and among areas with implied inferences for density dependence on population dynamics, and identifying spatially variable responses to temperature anomalies that are superimposed on an otherwise coherent latitudinal, temperature-correlated gradient in growth rates. While most of these observations are biologically plausible, we emphasize the risk of spurious correlations inherent in using such large data sets (in our case, 24661 increments from 6143 individuals). A possible example from our analyses is the statistically robust observation of sex-specific growth differences in some areas, but not others, and an age effect on this difference, again only in some areas. Sexspecific differences in growth rate are common, but the extent to which it differs between adjacent spatial areas in what appears to be a genetically homogeneous population is difficult to explain.

The analyses also indicate that, despite the magnitude of regional warming, the total effect of Temperature, alone and in various combinations, on growth rate variability in tiger flathead is relatively small. Nonetheless, a detailed hierarchical interrogation of the data both confirms a nonlinear relationship between absolute temperature and growth rate previously documented for a number of other inshore species locally and identifies more subtle responses to temperature trends and variability. The overall spatial variation of tiger flathead within-area temperature responses is consistent with previous studies of the effects of warming on southeast Australian coastal fish species (Thresher et al. 2007, Last et al. 2011, Neuheimer et al. 2011) and theoretical expectations of a direct temperature effect on the physiology and ecology of poikilotherms (Portner 2001, Portner and Farrell 2008). Qualitative assessment of our model results suggests a pejus temperature for tiger flathead of $\sim 16^{\circ} \mathrm{C}$. Hence, the large-scale relationship between tiger flathead interannual growth variation and bottom temperature appears to confirm an impact of climate change, likely via both direct physiological pathways (Portner 2001, Portner and Knust 2007) and indirectly through altering resource availability (McLeod et al. 2012) and interspecific interactions and synergies with other stressors (Ling et al. 2009). The magnitude of the temperature effect ranged among areas between $0.70 \%$ per year and $2.50 \%$ per year and is large enough to have pervasive intra- and interspecific biological and fishery relevance (Audzijonyte et al. $2013 a, b)$. Integrated across areas, however, the growth response to short-term temperature variation depended on an area's long-term temperature normal. Average growth was lowest where long-term temperature averages were coolest (more southerly), and in such areas, short-term positive temperature anomalies had only minor effects on growth rate. Toward the warmer end of the range, growth was not only on average faster, but also responded more strongly to positive short-term temperature anomalies, indicating some synergistic effect of warming from an already warm base. At the warm extreme, however, we saw indications of a pejus effect, with warm temperatures resulting in declining growth rates.

The different patterns in within- and among-individual growth variation across areas provide insight into the evolutionary processes underlying trait variation, as well as facilitating more nuanced predictions of future response to environmental change (Miner et al. 2005, 
Nussey et al. 2007). For example, the consistent levels of average within-individual plasticity (both across individuals and cohorts) evident in NC, CBS, ETAS, and WTAS is indicative of stabilizing selection on growth such that there is a common preferential response to warming (or cooling). Conversely, among-individual variation or temporal change in average reaction norm slopes (NSW, WBS, and EBS) could be evidence of directional selection where increased (or decreased) plasticity is favored in warmer (or cooler) conditions (Pigliucci 2005). Among-individual differences in average growth with temperature as seen in three areas may be caused by microevolution (selection in more recent and generally warmer years favoring faster growth rate genotypes) or indicative of a plastic response to multiyear environmental changes (reaction norm slopes stay the same, but average growth increases).

Our results indicate that while there is general agreement in the overall effects of temperature on tiger flathead growth, this phenotypic pattern can be brought about via a number of possible mechanisms, including differences in underpinning genetics or selective regimes. Future work determining the relative importance of these on trait averages and trait plasticity, as well as the additive or interactive role of other factors, such as fishing activity, and demography will provide a valuable mechanistic underpinning to the observed growth variation (Planque et al. 2010). Nonetheless, the preponderance for growth plasticity in relation to temperature across most areas suggests that tiger flathead will be able to, all else being equal, positively respond to continued warming through much of their range. This response may be facilitated by existing in situ adaptive scope or the poleward expansion of potentially warm, specialized genotypes from NSW and NC. At the equatorial range margin, where growth is currently highest, growth rates are likely to decrease as waters warm. Whether this ultimately leads to a range contraction is unknown and depends on the interplay among growth, survival, and reproduction. The poleward range margin is delineated by the availability of habitat (continental shelf waters), and it is unlikely to expand southward as the next land mass is Antarctica.

Finally, we propose that if aquatic hard-part researchers want to undertake ecological or evolutionary studies, they need to shift their focus away from methods developed for climatological reconstruction (for review, see Morrongiello et al. 2012). They should instead consider and analyze existing and future hardpart increment measurements as long-term, individualbased data sets rather than purposefully detrending and averaging away within and among individual variation. Such an individual-based perspective has facilitated the exploration of complex ecological and evolutionary questions in terrestrial animals (Clutton-Brock and Sheldon 2010) using, for example, reproductive phenology in great tits (Visser et al. 1998), body mass in Soay sheep (Ozgul et al. 2009), and senescence in ungulates
(Nussey et al. 2011). While this requires relatively large, high-quality data sets, there is no reason why similar advances cannot be made in aquatic systems, where hard-part studies can generate individual-based biochronologies decades and even centuries in length.

\section{ACKNOWLEDGMENTS}

We gratefully thank the Australian Fisheries Management Authority (AFMA) for permission to use their age and increment data; Simon Robertson and Kyne Krusic-Golub (Fish Ageing Services and formerly Central Ageing Facility) and Lachlan Barnes (New South Wales Department of Primary Industries [NSW DPI]) for providing aging training and increment measurements; David Smith, Neil Klaer (Commonwealth Scientific and Industrial Research Organisation [CSIRO]), and Jayson Semmens (Institute of Marine and Antarctic Studies) for helpful discussions on the paper's scope and the tiger flathead fishery; Geoff Hosack (CSIRO) and Sanford Weisberg (University of Minnesota) for statistical advice; and Matt Ives (NSW DPI) for NSW fishery data. David Smith, Neil Klaer, Tom Hobbs, and anonymous reviewers provided valuable comments that greatly improved the manuscript. J. R. Morrongiello was supported by an Office of the Chief Executive CSIRO Postdoctoral Fellowship.

\section{Literature Cited}

Anderson, J. T. 1988. A review of size dependent survival during pre-recruit stages of fishes in relation to recruitment. Journal of Northwest Atlantic Fishery Science 8:55-66.

Audzijonyte, A., A. Kuparinen, and E. A. Fulton. 2013a. How fast is fisheries-induced evolution? Quantitative analysis of modelling and empirical studies. Evolutionary Applications 6:585-595.

Audzijonyte, A., A. Kuparinen, R. Gorton, and E. A. Fulton. 2013b. Ecological consequences of body size decline in harvested fish species: positive feedback loops in trophic interactions amplify human impact. Biology Letters 9(2): 1103 .

Avens, L., et al. 2012. Population characteristics, age structure, and growth dynamics of neritic juvenile green turtles in the northeastern Gulf of Mexico. Marine Ecology Progress Series 458:213-229.

Barnes, L. M., C. A. Gray, and J. E. Williamson. 2011. Divergence of the growth characteristics and longevity of coexisting Platycephalidae (Pisces). Marine and Freshwater Research 62:1308-1317.

Baudron, A. R., C. L. Needle, A. D. Rijnsdorp, and C. Tara Marshall. 2014. Warming temperatures and smaller body sizes: synchronous changes in growth of North Sea fishes. Global Change Biology 20:1023-1031.

Biro, P. A., and J. R. Post. 2008. Rapid depletion of genotypes with fast growth and bold personality traits from harvested fish populations. Proceedings of the National Academy of Sciences USA 105:2919-2922.

Black, B. A. 2009. Climate-driven synchrony across tree, bivalve, and rockfish growth-increment chronologies of the northeast Pacific. Marine Ecology Progress Series 378:37-46.

Black, B. A., I. D. Schroeder, W. J. Sydeman, S. J. Bograd, B. K. Wells, and F. B. Schwing. 2011. Winter and summer upwelling modes and their biological importance in the California Current Ecosystem. Global Change Biology 17:2536-2545.

Bolker, B. M., M. E. Brooks, C. J. Clark, S. W. Geange, J. R. Poulsen, M. H. H. Stevens, and J. S. S. White. 2009. Generalized linear mixed models: a practical guide for ecology and evolution. Trends in Ecology and Evolution 24:127-135. 
Brannon, E. L., M. S. Powell, T. P. Quinn, and A. Talbot. 2004. Population structure of Columbia River Basin chinook salmon and steelhead trout. Reviews in Fisheries Science 12:99-232.

Brown, C. J., et al. 2011. Quantitative approaches in climate change ecology. Global Change Biology 17:3697-3713.

Büntgen, U., et al. 2014. European springtime temperature synchronises ibex horn growth across the eastern Swiss Alps. Ecology Letters 17:303-313.

Burnham, K. P., and D. R. Anderson. 2002. Model selection and inference: a practical information-theoretic approach. Second edition. Springer-Verlag, New York, New York, USA.

Campana, S. E. 1990. How reliable are growth backcalculations based on otoliths? Canadian Journal of Fisheries and Aquatic Sciences 47:2219-2227.

Campana, S. E. 2001. Accuracy, precision and quality control in age determination, including a review of the use and abuse of age validation methods. Journal of Fish Biology 59:197242.

Campana, S. E., and S. R. Thorrold. 2001. Otoliths, increments, and elements: keys to a comprehensive understanding of fish populations? Canadian Journal of Fisheries and Aquatic Sciences 58:30-38.

Carilli, J. E., R. D. Norris, B. Black, S. M. Walsh, and M. McField. 2010. Century-scale records of coral growth rates indicate that local stressors reduce coral thermal tolerance threshold. Global Change Biology 16:1247-1257.

Carrer, M., and C. Urbinati. 2004. Age-dependent tree-ring growth responses to climate in Larix decidua and Pinus cembra. Ecology 85:730-740.

Claeskens, G., and N. Hjort. 2008. Model selection and model averaging. Cambridge University Press, Cambridge, UK.

Clark, J. S., M. Wolosin, M. Dietze, I. Ibanez, S. LaDeau, M. Welsh, and B. Kloeppel. 2007. Tree growth inference and prediction from diameter censuses and ring widths. Ecological Applications 17:1942-1953.

Clutton-Brock, T., and B. C. Sheldon. 2010. Individuals and populations: the role of long-term, individual-based studies of animals in ecology and evolutionary biology. Trends in Ecology and Evolution 25:562-573.

Cook, E. R., B. M. Buckley, R. D. D'Arrigo, and M. J. Peterson. 2000. Warm-season temperatures since 1600 BC reconstructed from Tasmanian tree rings and their relationship to large-scale sea surface temperature anomalies. Climate Dynamics 16:79-91.

Cook, E. R., and L. A. Kairiukstis. 1990. Methods of dendrochronology: applications in the environmental sciences. Kluwer Academic Publishers, Dordrecht, The Netherlands.

Cooper, T. F., R. A. O’Leary, and J. M. Lough. 2012. Growth of Western Australian corals in the Anthropocene. Science 335:593-596.

Coulson, P., B. Black, I. Potter, and N. Hall. 2013. Sclerochronological studies reveal that patterns of otolith growth of adults of two co-occurring species of Platycephalidae are synchronised by water temperature variations. Marine Biology 161:383-393.

D'Arrigo, R., et al. 2006. The reconstructed Indonesian warm pool sea surface temperatures from tree rings and corals: linkages to Asian monsoon drought and El Niño-Southern Oscillation. Paleoceanography 21:PA3005.

De'ath, G., J. M. Lough, and K. E. Fabricius. 2009. Declining coral calcification on the Great Barrier Reef. Science 323:116-119.

Dellabianca, N. A., A. A. Hohn, R. N. P. Goodall, J. L. Pousa, C. D. Macleod, and M. Lima. 2012. Influence of climate oscillations on dentinal deposition in teeth of Commerson's dolphin. Global Change Biology 18:2477-2486.
Dingemanse, N. J., and N. A. Dochtermann. 2013. Quantifying individual variation in behaviour: mixed-effect modelling approaches. Journal of Animal Ecology 82:39-54.

Eveson, J. P., T. Polacheck, and G. M. Laslett. 2007. Consequences of assuming an incorrect error structure in von Bertalanffy growth models: a simulation study. Canadian Journal of Fisheries and Aquatic Sciences 64:602-617.

Francis, R. I. C. C. 1990. Back-calculation of fish length: a critical review. Journal of Fish Biology 36:883-904.

Fritts, H. C. 1976. Tree rings and climate. Academic Press, New York, New York, USA.

Gillanders, B. M., B. A. Black, M. G. Meekan, and M. A. Morrison. 2012. Climatic effects on the growth of a temperate reef fish from the Southern Hemisphere: a biochronological approach. Marine Biology 159:1327-1333.

Goldstein, H., W. J. Browne, and J. Rasbash. 2002. Partitioning variation in multilevel models. Understanding Statistics $1: 223-232$.

Gomon, M., D. Bray, and R. Kuiter, editors. 2008. Fishes of Australia's southern coast. New Holland Publishers, Sydney, Australia.

Greven, S., and T. Kneib. 2010. On the behaviour of marginal and conditional AIC in linear mixed models. Biometrika 97:773-789.

Haddon, M. 2011. Catch rate standardization 2010 (data from 1986 to 2009). Pages 44-179 in G. N. Tuck, editor. Stock assessment for the southern and eastern scalefish and shark fishery 2010. Part 2. Australian Fisheries Management Authority and CSIRO Marine and Atmospheric Sciences, Hobart, Tasmania, Australia.

Hagen, P. T., and T. J. Quinn. 1991. Long-term dynamics of young Pacific halibut: evidence of temperature-induced variation. Fisheries Research 11:283-306.

Harley, C. D. G., et al. 2006. The impacts of climate change in coastal marine systems. Ecology Letters 9:228-241.

Heino, M., U. Dieckmann, and O. R. Godo. 2002. Measuring probabilistic reaction norms for age and size at maturation. Evolution 56:669-678.

Heino, M., and O. R. Godo. 2002. Fisheries-induced selection pressures in the context of sustainable fisheries. Bulletin of Marine Science 70:639-656.

Helama, S., B. R. Schone, B. A. Black, and E. Dunca. 2006. Constructing long-term proxy series for aquatic environments with absolute dating control using a sclerochronological approach: introduction and advanced applications. Marine and Freshwater Research 57:591-599.

Helser, T. E., H. L. Lai, and B. A. Black. 2012. Bayesian hierarchical modeling of Pacific geoduck growth increment data and climate indices. Ecological Modelling 247:210-220.

Hewitt, J. E., S. F. Thrush, P. K. Dayton, and E. Bonsdorff. 2007. The effect of spatial and temporal heterogeneity on the design and analysis of empirical studies of scale-dependent systems. American Naturalist 169:398-408.

Hobday, A. J., and J. M. Lough. 2011. Projected climate change in Australian marine and freshwater environments. Marine and Freshwater Research 62:1000-1014.

Hooten, M. B., and N. T. Hobbs. 2015. A guide to Bayesian model selection for ecologists. Ecological Monographs 85:328.

Johnson, C. R., et al. 2011. Climate change cascades: shifts in oceanography, species' ranges and subtidal marine community dynamics in eastern Tasmania. Journal of Experimental Marine Biology and Ecology 400:17-32.

Jorgensen, C., et al. 2007. Managing evolving fish stocks. Science 318:1247-1248.

Kearney, M., and W. Porter. 2009. Mechanistic niche modelling: combining physiological and spatial data to predict species' ranges. Ecology Letters 12:334-350. 
Klaer, N. 2010. Tiger flathead (Neoplatycephalus richardsoni) stock assessment based on data up to 2009. CSIRO Marine and Atmospheric Research, Hobart, Tasmania, Australia.

Klaer, N. L. 2004. Abundance indices for main commercial fish species caught by trawl from the south-eastern Australian continental shelf from 1918 to 1957. Marine and Freshwater Research 55:561-571.

Knuckey, I., C. Grieve, and D. C. Smith. 1999. Evolution of the integrated scientific monitoring programme in Australia's South East Fishery. Pages 231-248 in C. P. Nolan, editor. Proceedings of the International Conference on Integrated Fisheries Monitoring, Sydney, Australia, February 1-5 1999. FAO, Rome, Italy.

Lapointe-Garant, M. P., J. G. Huang, G. Gea-Izquierdo, F. Raulier, P. Bernier, and F. Berninger. 2010. Use of tree rings to study the effect of climate change on trembling aspen in Quebec. Global Change Biology 16:2039-2051.

Last, P. R., W. T. White, D. C. Gledhill, A. J. Hobday, R. Brown, G. J. Edgar, and G. Pecl. 2011. Long-term shifts in abundance and distribution of a temperate fish fauna: a response to climate change and fishing practices. Global Ecology and Biogeography 20:58-72.

Leites, L. P., A. P. Robinson, G. E. Rehfeldt, J. D. Marshall, and N. L. Crookston. 2012. Height-growth response to climatic changes differs among populations of Douglas-fir: a novel analysis of historic data. Ecological Applications 22:154-165.

Ling, S. D., C. R. Johnson, S. D. Frusher, and K. R. Ridgway. 2009. Overfishing reduces resilience of kelp beds to climatedriven catastrophic phase shift. Proceedings of the National Academy of Sciences USA 106:22341-22345.

Lough, J. M., and T. F. Cooper. 2011. New insights from coral growth band studies in an era of rapid environmental change. Earth-Science Reviews 108:170-184.

McLeod, D. J., A. J. Hobday, J. M. Lyle, and D. C. Welsford. 2012. A prey-related shift in the abundance of small pelagic fish in eastern Tasmania? ICES Journal of Marine Science 69:953-960.

Miner, B. G., S. E. Sultan, S. G. Morgan, D. K. Padilla, and R. A. Relyea. 2005. Ecological consequences of phenotypic plasticity. Trends in Ecology and Evolution 20:685-692.

Morison, A. K., S. G. Robertson, and D. C. Smith. 1998. An integrated system for production fish aging: image analysis and quality assurance. North American Journal of Fisheries Management 18:587-598.

Morrongiello, J. R., D. A. Crook, A. J. King, D. S. L. Ramsey, and P. Brown. 2011. Impacts of drought and predicted effects of climate change on fish growth in temperate Australian lakes. Global Change Biology 17:745-755.

Morrongiello, J. R., R. E. Thresher, and D. C. Smith. 2012. Aquatic biochronologies and climate change. Nature Climate Change 2:849-857.

Morrongiello, J. R., C. T. Walsh, C. A. Gray, J. R. Stocks, and D. A. Crook. 2014. Environmental change drives long-term recruitment and growth variation in an estuarine fish. Global Change Biology 20:1844-1860.

Murphy, H. M., G. P. Jenkins, P. A. Hamer, and S. E. Swearer. 2013. Interannual variation in larval abundance and growth in snapper Chrysophrys auratus (Sparidae) is related to prey availability and temperature. Marine Ecology Progress Series 487:151-162.

Nakagawa, S., and H. Schielzeth. 2013. A general and simple method for obtaining $R^{2}$ from generalized linear mixedeffects models. Methods in Ecology and Evolution 4:133142.

Nehrbass-Ahles, C., et al. 2014. The influence of sampling design on tree-ring based quantification of forest growth. Global Change Biology 20(9):2867-2885.
Neuheimer, A. B., R. E. Thresher, J. M. Lyle, and J. M. Semmens. 2011. Tolerance limit for fish growth exceeded by warming waters. Nature Climate Change 1:110-113.

Nussey, D. H., T. Coulson, D. Delorme, T. H. Clutton-Brock, J. M. Pemberton, M. Festa-Bianchet, and J. M. Gaillard. 2011. Patterns of body mass senescence and selective disappearance differ among three species of free-living ungulates. Ecology 92:1936-1947.

Nussey, D. H., A. J. Wilson, and J. E. Brommer. 2007. The evolutionary ecology of individual phenotypic plasticity in wild populations. Journal of Evolutionary Biology 20:831844.

Ozgul, A., S. Tuljapurkar, T. G. Benton, J. M. Pemberton, T. H. Clutton-Brock, and T. Coulson. 2009. The dynamics of phenotypic change and the shrinking sheep of St. Kilda. Science 325:464-467.

Parmesan, C., C. Duarte, E. Poloczanska, A. J. Richardson, and M. C. Singer. 2011. Overstretching attribution. Nature Climate Change 1:2-4.

Pigliucci, M. 2005. Evolution of phenotypic plasticity: where are we going now? Trends in Ecology and Evolution 20:481486.

Pilling, G. M., G. P. Kirkwood, and S. G. Walker. 2002. An improved method for estimating individual growth variability in fish, and the correlation between von Bertalanffy growth parameters. Canadian Journal of Fisheries and Aquatic Sciences 59:424-432.

Pinheiro, J. C., and D. M. Bates. 2000. Mixed effects models in S and S-plus. Spinger-Verlag, New York, New York, USA.

Planque, B., J. M. Fromentin, P. Cury, K. F. Drinkwater, S. Jennings, R. I. Perry, and S. Kifani. 2010. How does fishing alter marine populations and ecosystems sensitivity to climate? Journal of Marine Systems 79:403-417.

Portner, H. O. 2001. Climate change and temperaturedependent biogeography: oxygen limitation of thermal tolerance in animals. Naturwissenschaften 88:137-146.

Portner, H. O., and A. P. Farrell. 2008. Physiology and climate change. Science 322:690-692.

Portner, H. O., and R. Knust. 2007. Climate change affects marine fishes through the oxygen limitation of thermal tolerance. Science 315:95-97.

Pyke, G. H., and P. R. Ehrlich. 2010. Biological collections and ecological/environmental research: a review, some observations and a look to the future. Biological Reviews 85:247266.

R Development Core Team. 2013. R: a language and environment for statistical computing. R Foundation for Statistical Computing, Vienna, Austria. www.r-project.org

Rayner, N. A., et al. 2003. Global analyses of sea surface temperature, sea ice, and night marine air temperature since the late nineteenth century. Journal of Geophysical Research-Atmospheres 108:D14.

Richardson, A. J., and E. S. Poloczanska. 2008. Ocean science-under-resourced, under threat. Science 320:12941295.

Ricker, W. E. 1969. Effects of size-selective mortality and sampling bias on estimates of growth, mortality, production and yield. Journal of the Fisheries Research Board of Canada 26:479-541.

Ridgway, K. R. 2007. Long-term trend and decadal variability of the southward penetration of the East Australian Current. Geophysical Research Letters 34:L13613.

Ridgway, K. R., J. R. Dunn, M. Cahill, and D. Griffin. 2006. SynTS: a 3D ocean observational analysis for the Australian region (poster). 15-years Progress in Altimetry, ESA Symposium, Venice, Italy. http://www.marine.csiro.au/ eez_data/doc/synTS.html

Rountrey, A. N., P. G. Coulson, J. J. Meeuwig, and M. Meekan. 2014. Water temperature and fish growth: otoliths 
predict growth patterns of a marine fish in a changing climate. Global Change Biology 20:2450-2458.

Rowling, K., A. Hegarty, and M. Ives, editors. 2010. Status of fisheries resources in NSW 2008/09. Industry and Investment NSW, Cronulla, New South Wales, Australia.

Rowling, K. R. 1994. Tiger flathead, Neoplatycephalus richardsoni. Pages 124-136 in R. D. J. Tilzey, editor. The South East Fishery: a scientific review with particular reference to quota management. Bureau of Resource Sciences, Canberra, Australia.

Rowling, K. R., and D. D. Reid. 1992. Effect of temporal changes in size composition on estimates of von Bertalanffy growth parameters for gemfish, Rexea solandri (Cuvier), Gempylidae. Australian Journal of Marine and Freshwater Research 43:1229-1239.

Sahqvist, P., et al. Status of key Australian fish stocks reports 2012. Fisheries Research and Development Corporation, Canberra, Australia.

Sainsbury, K. J. 1980. Effect of individual variability on the von Bertalanffy growth equation. Canadian Journal of Fisheries and Aquatic Sciences 37:241-247.

Shelton, A. O., W. H. Satterthwaite, M. P. Beakes, S. B. Munch, S. M. Sogard, and M. Mangel. 2013. Separating intrinsic and environmental contributions to growth and their population consequences. American Naturalist 181:799-814.

Sinclair, A. F., D. P. Swain, and J. M. Hanson. $2002 a$. Measuring changes in the direction and magnitude of sizeselective mortality in a commercial fish population. Canadian Journal of Fisheries and Aquatic Sciences 59:361-371.

Sinclair, A. F., D. P. Swain, and J. M. Hanson. $2002 b$. Disentangling the effects of size-selective mortality, density, and temperature on length-at-age. Canadian Journal of Fisheries and Aquatic Sciences 59:372-382.

Thresher, R. E., J. A. Koslow, A. K. Morison, and D. C. Smith. 2007. Depth-mediated reversal of the effects of climate change on long-term growth rates of exploited marine fish. Proceedings of the National Academy of Sciences USA 104:7461-7465.

Tilzey, R. D. J., and K. R. Rowling. 2001. History of Australia's South East Fishery: a scientist's perspective. Marine and Freshwater Research 52:361-375.

Tonkin, Z. D., A. J. King, A. I. Robertson, and D. S. L. Ramsey. 2011. Early fish growth varies in response to components of the flow regime in a temperate floodplain river. Freshwater Biology 56:1769-1782.
Trumble, S. J., E. M. Robinson, M. Berman-Kowalewski, C. W. Potter, and S. Usenko. 2013. Blue whale earplug reveals lifetime contaminant exposure and hormone profiles. Proceedings of the National Academy of Sciences USA 110:16922-16926.

Vaida, F., and S. Blanchard. 2005. Conditional Akaike information for mixed-effects models. Biometrika 92:351370.

van de Pol, M. V., and J. Wright. 2009. A simple method for distinguishing within- versus between-subject effects using mixed models. Animal Behaviour 77:753-758.

Visser, M. E., A. J. van Noordwijk, J. M. Tinbergen, and C. M. Lessells. 1998. Warmer springs lead to mistimed reproduction in great tits (Parus major). Proceedings of the Royal Society of London Series B 265:1867-1870.

Wang, W., and A. Gelman. 2014. Difficulty of selecting among multilevel models using predictive accuracy. Statistics at its Interface 7:1-8.

Weatherley, A. H., and H. S. Gill, editors. 1987. The biology of fish growth. Academic Press, London, UK.

Weisberg, S. 1993. Using hard-part increment data to estimate age and environmental effects. Canadian Journal of Fisheries and Aquatic Sciences 50:1229-1237.

Weisberg, S., G. Spangler, and L. S. Richmond. 2010. Mixed effects models for fish growth. Canadian Journal of Fisheries and Aquatic Sciences 67:269-277.

Werner, E. E., and B. R. Anholt. 1993. Ecological consequences of the trade-off between growth and mortality rates mediated by foraging activity. American Naturalist 142:242-272.

Whitten, A. R., N. L. Klaer, G. N. Tuck, and R. W. Day. 2013. Accounting for cohort-specific variable growth in fisheries stock assessments: a case study from south-eastern Australia. Fisheries Research 142:27-36.

Woodhams, J., I. Stobutzki, S. Viera, R. Curtotti, and G. A. Begg, editors. 2011. Fishery status reports 2010: status of fish stocks and fisheries managed by the Australian Government. Australian Bureau of Agricultural and Resource Economics and Sciences, Canberra, Australia.

Zeger, S. L., and K. Y. Liang. 1986. Longitudinal data analysis for discrete and continuous outcomes. Biometrics 42:121130.

Zuur, A. F., E. N. Ieno, N. J. Walker, A. A. Saveliev, and G. M. Smith. 2009. Mixed effects models and extensions in ecology with R. Springer, New York, New York, USA.

\section{Supplemental Material}

\section{Ecological Archives}

Appendices A-G and the Supplement are available online: http://dx.doi.org/10.1890/13-2355.1.sm

\section{Data Availability}

Data associated with this paper have been deposited in Dryad Digital Repository: http://dx.doi.org/10.5061/dryad.q9h64 